NBER WORKING PAPER SERIES

\title{
FIRM-SPECIFIC CAPITAL, NOMINAL RIGIDITIES AND THE BUSINESS CYCLE
}

\author{
David Altig \\ Lawrence J. Christiano \\ Martin Eichenbaum \\ Jesper Linde \\ Working Paper 11034 \\ http://www.nber.org/papers/w11034
}

\author{
NATIONAL BUREAU OF ECONOMIC RESEARCH \\ 1050 Massachusetts Avenue \\ Cambridge, MA 02138 \\ January 2005
}

We are grateful for the comments of David Andolfatto, Gadi Barlevy, Andy Levin and Harald Uhlig. In addition we have benefitted from the reactions of the participants in the Third Banco de Portugal Conference in Monetary Economics, Lisbon, Portugal, June 10, 2004, as well as in the conference on Dynamic Models and Monetary Policymaking, September 22-24, 2004, held at the Federal Reserve Bank of Cleveland. We are also grateful for the comments of the participants in the 'Impulses and Propagations' workshop of the NBER Summer Institute in the week of July 19, 2004. Finally, we are particularly grateful for the insights and for the research assistance of Riccardo DiCecio. The views expressed herein are those of the author(s) and do not necessarily reflect the views of the National Bureau of Economic Research.

(c) 2005 by David Altig, Lawrence J. Christiano, Martin Eichenbaum, and Jesper Linde. All rights reserved. Short sections of text, not to exceed two paragraphs, may be quoted without explicit permission provided that full credit, including $\odot$ notice, is given to the source. 
Firm-Specific Capital, Nominal Rigidities and the Business Cycle

David Altig, Lawrence J. Christiano, Martin Eichenbaum, and Jesper Linde

NBER Working Paper No. 11034

January 2005

JEL No. E3, E4, E5

\author{
$\underline{\text { ABSTRACT }}$ \\ Macroeconomic and microeconomic data paint conflicting pictures of price behavior. \\ Macroeconomic data suggest that inflation is inertial. Microeconomic data indicate that firms change \\ prices frequently. We formulate and estimate a model which resolves this apparent micro - macro \\ conflict. Our model is consistent with post-war U.S. evidence on inflation inertia even though firms \\ re-optimize prices on average once every 1.5 quarters. The key feature of our model is that capital \\ is firm-specific and pre-determined within a period. \\ David Altig \\ Federal Reserve Bank of Cleveland \\ david.e.altig@clev.frb.org \\ Lawrence Christiano \\ Department of Economics \\ Northwestern University \\ 2003 Sheridan Road \\ Evanston, IL 60208 \\ and NBER \\ 1-christiano@northwestern.edu \\ Martin Eichenbaum \\ Department of Economics \\ Northwestern University \\ 2003 Sheridan Road \\ Evanston, IL 60208 \\ and NBER \\ eich@northwestern.edu \\ Jesper Linde \\ Sveriges Riksbank \\ jesper.linde@riksbank.se
}




\section{Introduction}

Microeconomic and macroeconomic and data paint conflicting pictures of price behavior. Microeconomic data indicate that firms change prices frequently. Macroeconomic data suggest that inflation is inertial. The conflict is obvious in recent macroeconomic models which account for inflation inertia by assuming that firms re-optimize their prices every six quarters or even less often. ${ }^{1}$ The assumption in these models seems implausible to us. We are sympathetic to the view taken by Bils and Klenow (2004), Golosov and Lucas (2003) and Klenow and Kryvtsov (2004) that firms re-optimize prices more frequently than once every 2 quarters. $^{2}$

We formulate and estimate a model which resolves the apparent micro-macro pricing conflict. Our model is consistent with the evidence of inflation inertia even though firms re-optimize prices on average once every 1.5 quarters. In addition, our model accounts for the dynamic response of 10 key U.S. macro time series to monetary policy shocks, neutral technology shocks and capital embodied shocks. ${ }^{3}$

In our model aggregate inflation is inertial despite the fact that firms change prices frequently. The inertia reflects that when they do change prices, they do so by a small amount. Firms change prices by a small amount because each firm's short run marginal cost curve is increasing in its own output. ${ }^{4}$ This positive dependency reflects our assumption that in any given period, a firm's capital stock is predetermined. In standard equilibrium business cycle models a firm's capital stock is not pre-determined and all factors of production, including capital, can be instantaneously transferred across firms, without any cost, in perfectly competitive markets. These assumptions are empirically unrealistic but are defended on the grounds of tractability. The hope is that these assumptions are innocuous and do not affect major model properties. In fact these assumptions matter a lot.

In our model, a firm's capital is pre-determined and can only be changed over time by varying the rate of investment. These properties follow from our assumption that capital is completely firm-specific. ${ }^{5}$ Our assumptions about capital imply that a firm's marginal cost

\footnotetext{
${ }^{1}$ For example, Gali and Gertler (1999) and Eichenbaum and Fisher (2004) find that estimated versions of standard Calvo pricing models imply that firms re-optimize prices roughly once every six quarters. Smets and Wouters' (2003) estimate that firms re-optimize prices on average once every nine quarters.

${ }^{2}$ For example, in calibrating their model to the micro data, Golosov and Lucas (2003, Table 1, page 20) select parameters to ensure that firms re-optimize prices on average once every 1.5 quarters.

${ }^{3}$ See also DiCecio (2004) for a multi-sectoral general equilibrium model which allows for the same three shocks that we consider. Also, Edge (2004) considers a general equilibrium model with two types of technology shocks.

${ }^{4}$ For early discussions of this idea, see Ball and Romer (1990) and Kimball (1995).

${ }^{5}$ See, for example, Sbordone (2002) for an early example of a dynamic general equilibrium model with firm-specific capital. Unlike our model, Sbordone assumes that a firm can never change the quantity of its capital. Our approach follows Woodford (2003, 2004) most closely, in allowing for firm-specific capital and the possibility of investment. Other recent work which allows for firm-specific capital includes Coenen
} 
curve depends positively on its output level. ${ }^{6}$ To see the impact of this dependence on pricing decisions, consider a firm that contemplates raising its price. The firm understands that a higher price implies less demand and less output. A lower level of output reduces marginal cost, which other things equal, induces a firm to post a lower price. Thus, the dependence of marginal cost on firm-level output acts as a countervailing influence on a firm's incentives to raise price. This countervailing influence is why aggregate inflation responds less to a given aggregate marginal cost shock when capital is firm-specific.

Anything, including firm-specificity of some other factor of production or adjustment costs in labor, which causes a firm's marginal cost to be an increasing function of its output works in the same direction as firm-specificity of capital. This fact is important because our assumption that the firm's entire stock of capital is predetermined probably goes too far from an empirical standpoint.

We conduct our analysis using two versions of the model analyzed by Christiano, Eichenbaum, and Evans (2005): in one, capital is homogeneous whereas in the other, it is firmspecific. We refer to these models as the homogeneous and firm-specific capital models, respectively. We show that the only difference between the log-linearized equations characterizing equilibrium in the two models pertains to the equation relating inflation to marginal costs. The form of this equation is identical in both models: inflation at time $t$ is equal to discounted expected inflation at time $t+1$ plus a reduced form coefficient, $\gamma$, multiplying time $t$ economy-wide average real marginal cost. The difference between the two models lies in the mapping between the structural parameters and $\gamma$.

In the homogeneous capital model, $\gamma$ depends only on agents' discount rates and on the fraction, $1-\xi_{p}$, of firms that re-optimize prices within the quarter. In the firm-specific capital model, $\gamma$ is a function of a broader set of the structural parameters. For example, the more costly it is for a firm to vary capital utilization, the steeper is its marginal cost curve and hence the smaller is $\gamma$. A different example is that in the firm-specific capital model, the parameter $\gamma$ is smaller the more elastic is the firm's demand curve. ${ }^{7}$ This result reflects that the more elastic is a firm's demand, the greater is the reduction in demand and output in response to a given price increase. A bigger fall in output implies a bigger fall in marginal cost which reduces a firm's incentive to raise its price.

The only way that $\xi_{p}$ enters into the reduced form of the two models is via this parameter's impact on $\gamma$. If we parameterize the two models in terms of $\gamma$ rather than $\xi_{p}$, they have identical implications for all aggregate quantities and prices. This observational equivalence

and Levin (2004), de Walque Smets and Wouters (2004), Eichenbaum and Fisher (2004), Sveen and Weinke (2004a,b).

${ }^{6} \mathrm{~A}$ closely related assumption is that capital is not firm-specific, but there are internal costs of adjusting capital

${ }^{7}$ See Ball and Romer (1990) and Kimball (1995) for an early discussion of this point. 
result implies that we can estimate the model in terms of $\gamma$ without taking a stand on whether capital is firm-specific or homogeneous.

The observational equivalence result also implies that we cannot assess the relative plausibility of the homogeneous and firm-specific capital models using macro data. However, the two models have very different implications for micro data. To assess the relative plausibility of the two models, we focus on the mean time between price re-optimization, and the dynamic response of the cross - firm distribution of production and prices to aggregate shocks. These implications depend on the parameters of the model, which we estimate.

We follow Christiano et al (2005) in choosing model parameter values to minimize the differences between the dynamic response to shocks in the model and the analog objects estimated using a vector autoregressive representation of 10 post-war quarterly U.S. time series. To compute vector autoregression (VAR) based impulse response functions, we use identification assumptions satisfied by our economic model: the only shocks that affect productivity in the long run are innovations to neutral and capital-embodied technology; the only shock that affects the price of investment goods in the long run is an innovation to capital-embodied technology ${ }^{8}$ monetary policy shocks have a contemporaneous impact on the interest rate, but they do not have a contemporaneous impact on aggregate quantities and prices. We estimate that together these three shocks account for almost 50 percent of cyclical fluctuations in aggregate output and other aggregate quantities.

We now discuss the key properties of our estimated model. First, the model does a good job of accounting for the estimated response of the economy to both monetary policy and technology shocks. Second, according to our point estimates, households re-optimize wages on average once every 3.6 quarters. Third, our point estimate of $\gamma$ is 0.040 . In the homogeneous capital version of the model, this value of $\gamma$ implies that firms change prices on average once every 5.6 quarters. But in the firm-specific capital model, this value of $\gamma$ implies that firms change price on average once every 1.5 quarters. The reason why the models have such different implications for firms' pricing behavior is that according to our estimates, firms' demand curves are highly elastic and their marginal cost curves are very steep.

Finally, we show that the two versions of the model differ sharply in terms of their implications for the cross-sectional distribution of production. In the homogeneous capital model, a very small fraction of firms produce the bulk of the economy's output in the periods after a monetary policy shock. The implications of the firm-specific model are much less extreme. We conclude that both the homogeneous and firm-specific capital models can account for inflation inertia and the response of the economy to monetary policy and technology shocks. But only the firm-specific model can reconcile the micro-macro pricing

\footnotetext{
${ }^{8}$ Our strategy for identifying technology shocks follows Fisher (2003).
} 
conflict without obviously unpalatable micro implications.

The quality of our estimation strategy depends on the ability of identified VARs to generate reliable estimates of the dynamic response of economic variables to shocks. The literature reports several examples in which VAR methods for estimating dynamic response functions are inaccurate. ${ }^{9}$ In Appendix A we discuss the reliability of VAR methods in our application. We assess these methods using Monte Carlo simulation methods. We proceed by generating artificial data using our estimated equilibrium model. Because there are only three shocks in our model, we must introduce additional sources of variation in the data generating mechanism to estimate our 10-variable VAR with artificial data. The way these disturbances are selected has an important impact on the outcome of the Monte Carlo simulations. ${ }^{10}$ Our estimated VAR provides a natural estimate of this source of variation. We find that in terms of bias and sampling uncertainty, the Monte Carlo performance of our VAR based estimates of impulse response functions is very good.

The paper is organized as follows. In Section 2 we describe our basic model economy. Section 3 describes our VAR-based estimation procedure. Section 4 presents our VAR-based impulse response functions and their properties. Sections 5 and 6 present and analyze the results of estimating our model. Section 7 discusses the implications of the homogeneous and firm-specific capital models for the cross-firm distribution of prices and production in the wake of a monetary policy shock. Section 8 discusses the accuracy of our VAR based estimator of impulse response functions. Section 9 concludes.

\section{The Model Economy}

In this section we describe the homogeneous and firm-specific capital models.

\subsection{The homogeneous capital Model}

The model economy is populated by goods-producing firms, households and the government.

\subsubsection{Final Good Firms}

At time $t$, a final consumption good, $Y_{t}$, is produced by a perfectly competitive, representative firm. The firm produces the final good by combining a continuum of intermediate goods,

\footnotetext{
${ }^{9}$ See, for example, Chari, Kehoe and McGrattan (2004), Cooley and Dwyer (1998), and Erceg, Guerrieri and Gust (2003).

${ }^{10}$ For example, Erceg, Guerrieri and Gust (2003) suggest that if the shocks excluded from the model analysis have persistent (though not permanent) effects on labor productivity, VAR methods will, in small samples, tend to confound the effects of these with the effects of neutral and capital-embodied technology shocks.
} 
indexed by $i \in[0,1]$, using the technology

$$
Y_{t}=\left[\int_{0}^{1} y_{t}(i)^{\frac{1}{\lambda_{f}}} d i\right]^{\lambda_{f}}
$$

where $1 \leq \lambda_{f}<\infty$ and $y_{t}(i)$ denotes the time $t$ input of intermediate good $i$. The firm takes its output price, $P_{t}$, and its input prices, $P_{t}(i)$, as given and beyond its control. The first order necessary condition for profit maximization is:

$$
\left(\frac{P_{t}}{P_{t}(i)}\right)^{\frac{\lambda_{f}}{\lambda_{f}-1}}=\frac{y_{t}(i)}{Y_{t}}
$$

Integrating (2.2) and imposing (2.1), we obtain the following relationship between the price of the final good and the price of the intermediate good:

$$
P_{t}=\left[\int_{0}^{1} P_{t}(i)^{\frac{1}{1-\lambda_{f}}} d i\right]^{\left(1-\lambda_{f}\right)} .
$$

\subsubsection{Intermediate Good Firms}

Intermediate good $i \in(0,1)$ is produced by a monopolist using the following technology:

$$
y_{t}(i)= \begin{cases}K_{t}(i)^{\alpha}\left(z_{t} h_{t}(i)\right)^{1-\alpha}-\phi z_{t}^{*} & \text { if } K_{t}(i)^{\alpha}\left(z_{t} h_{t}(i)\right)^{1-\alpha} \geq \phi z_{t}^{*} \\ 0 & \text { otherwise }\end{cases}
$$

where $0<\alpha<1$. Here, $h_{t}(i)$ and $K_{t}(i)$ denote time $t$ labor and capital services used to produce the $i^{\text {th }}$ intermediate good. The variable, $z_{t}$, represents a time $t$ shock to the technology for producing intermediate output. We refer to $z_{t}$ as a neutral technology shock and denote its growth rate, $z_{t} / z_{t-1}$, by $\mu_{z t}$. The non-negative scalar, $\phi$, parameterizes fixed costs of production. The variable, $z_{t}^{*}$, is given by:

$$
z_{t}^{*}=\Upsilon_{t}^{\frac{\alpha}{1-\alpha}} z_{t}
$$

where $\Upsilon_{t}$ represents a time $t$ shock to capital embodied technology. We choose the structure of the firm's fixed cost in (2.5) to ensure that the nonstochastic steady state of the economy exhibits balanced growth path. We denote the growth rate of $z_{t}^{*}$ and $\Upsilon_{t}$ by $\mu_{z_{t}^{*}}$ and $\mu_{\Upsilon_{t}}$ respectively, so that:

$$
\mu_{z^{*}, t}=\left(\mu_{\Upsilon, t}\right)^{\frac{\alpha}{1-\alpha}} \mu_{z, t}
$$

Throughout, we rule out entry into and exit from the production of intermediate good $i$.

Let $\hat{\mu}_{z, t}$ denote $\left(\mu_{z, t}-\mu_{z}\right) / \mu_{z}$, where $\mu_{z}$ is the growth rate of $\mu_{z, t}$ in non-stochastic steady state. We define all variables with a hat in an analogous manner. The variables $\hat{\mu}_{z, t}$ evolves according to:

$$
\hat{\mu}_{z, t}=\rho_{\mu_{z}} \hat{\mu}_{z, t-1}+\varepsilon_{\mu_{z}, t}
$$


where $\left|\rho_{\mu_{Z}}\right|<1$ and $\varepsilon_{\mu_{Z}, t}$ is uncorrelated over time and with all other shocks in the model. We denote the standard deviation of $\varepsilon_{\mu_{z}, t}$ by $\sigma_{\mu_{z}}$. Similarly, we assume:

$$
\hat{\mu}_{\Upsilon, t}=\rho_{\mu_{\Upsilon}} \hat{\mu}_{\Upsilon, t-1}+\varepsilon_{\mu_{\Upsilon}, t},
$$

where $\varepsilon_{\mu_{\Upsilon}, t}$ has the same properties as $\varepsilon_{\mu_{z}, t}$. We denote the standard deviation of $\varepsilon_{\mu_{\Upsilon}, t}$ by $\sigma_{\mu_{\Upsilon}}$.

Intermediate good firms rent capital and labor in perfectly competitive factor markets. Profits are distributed to households at the end of each time period. Let $P_{t} r_{t}^{k}$ and $P_{t} w_{t}$ denote the nominal rental rate on capital services and the wage rate, respectively. We assume that the firm must borrow the wage bill in advance at the gross interest rate, $R_{t}$.

Firms set prices according to a variant of the mechanism spelled out in Calvo (1983). In each period, an intermediate goods firm faces a constant probability, $1-\xi_{p}$, of being able to re-optimize its nominal price. The ability to re-optimize prices is independent across firms and time. As in Christiano et al (2005), we assume that a firm which cannot re-optimize its price sets $P_{t}(i)$ according to:

$$
P_{t}(i)=\pi_{t-1} P_{t-1}(i) .
$$

Here, $\pi_{t}$ denotes aggregate inflation, $P_{t} / P_{t-1}$.

An intermediate goods firm's objective function is:

$$
E_{t} \sum_{j=0}^{\infty} \beta^{j} v_{t+j}\left[P_{t+j}(i) y_{t+j}(i)-P_{t+j}\left(w_{t+j} R_{t+j} h_{t+j}(i)+r_{t+j}^{k} K_{t+j}(i)\right)\right]
$$

where $E_{t}$ is the expectation operator conditioned on time zero information. The term, $\beta^{t} v_{t+j}$, is proportional to the state-contingent marginal value of a dollar to a household. ${ }^{11}$ Also, $\beta$ is a scalar between zero and unity. The timing of events for a firm is as follows. At the beginning of period $t$, the firm observes the technology shocks and sets its price, $P_{t}(i)$. Then, a shock to monetary policy is realized, as is the demand for the firm's product. The firm then chooses productive inputs to satisfy this demand. The problem of the $i^{\text {th }}$ intermediate good firm is to choose prices, employment and capital services, subject to the timing and other constraints described above, to maximize (2.10).

\subsubsection{Households}

There is a continuum of households, indexed by $j \in(0,1)$. The sequence of events in a period for a household is as follows. First, the technology shocks are realized. Second, the household makes its consumption and investment decisions; decides how many units of capital services to supply to rental markets; and purchases securities whose payoffs are

\footnotetext{
${ }^{11}$ The constant of proportionality is the probability of the relevant state of the world.
} 
contingent upon whether it can re-optimize its wage decision. Third, the household sets its wage rate. Fourth, the monetary policy shock is realized. Finally, the household allocates its beginning of period cash between deposits at the financial intermediary and cash to be used in consumption transactions.

Each household is a monopoly supplier of a differentiated labor service, and sets its wage subject to Calvo-style wage frictions. In general, households earn different wage rates and work different amounts. A straightforward extension of arguments in Erceg, Henderson, and Levin (2000) and Woodford (1996) establishes that in the presence of state contingent securities, households are homogeneous with respect to consumption and asset holdings. Our notation reflects this result.

The preferences of the $j^{\text {th }}$ household are given by:

$$
E_{t}^{j} \sum_{l=0}^{\infty} \beta^{l-t}\left[\log \left(C_{t+l}-b C_{t+l-1}\right)-\psi_{L} \frac{h_{j, t+l}^{2}}{2}\right],
$$

where $\psi_{L} \geq 0$ and $E_{t}^{j}$ is the time $t$ expectation operator, conditional on household $j$ 's time $t$ information set. The variable, $C_{t}$, denotes time $t$ consumption and $h_{j t}$ denotes time $t$ hours worked. When $b>0,(2.11)$ exhibits habit formation in consumption preferences.

The household's asset evolution equation is given by:

$$
\begin{aligned}
M_{t+1}= & R_{t}\left[M_{t}-Q_{t}+\left(x_{t}-1\right) M_{t}^{a}\right]+A_{j, t}+Q_{t}+W_{j, t} h_{j, t} \\
& +P_{t} r_{t}^{k} u_{t} \bar{K}_{t}+D_{t}-\left(1+\eta\left(V_{t}\right)\right) P_{t} C_{t}-P_{t} \Upsilon_{t}^{-1}\left(I_{t}+a\left(u_{t}\right) \bar{K}_{t}\right) .
\end{aligned}
$$

Here, $M_{t}, Q_{t}$ and $W_{j, t}$ denote the household's beginning of period $t$ stock of money, cash balances and time $t$ nominal wage rate, respectively. In addition, $\bar{K}_{t}, u_{t}, D_{t}$ and $A_{j, t}$ denote, the household's physical stock of capital, the capital utilization rate, firm profits and the net cash inflow from participating in state-contingent securities at time $t$. The variable $x_{t}$ represents the gross growth rate of the economy-wide per capita stock of money, $M_{t}^{a}$. The quantity $\left(x_{t}-1\right) M_{t}^{a}$ is a lump-sum payment made to households by the monetary authority. The household deposits $M_{t}-Q_{t}+\left(x_{t}-1\right) M_{t}^{a}$ with a financial intermediary. The variable, $R_{t}$, denotes the gross interest rate.

The variable, $V_{t}$, denotes the time $t$ velocity of the household's cash balances:

$$
V_{t}=\frac{P_{t} C_{t}}{Q_{t}}
$$

where $\eta\left(V_{t}\right)$ is increasing and convex. The function $\eta\left(V_{t}\right)$ captures the role of cash balances in facilitating transactions. Similar specifications have been used by a variety of authors including Sims (1994) and Schmitt-Grohe and Uribe (2004). For the quantitative analysis of our model, we require the level and the first two derivatives of the transactions function, $\eta(V)$, evaluated in steady state. We denote these by $\eta, \eta^{\prime}$, and $\eta^{\prime \prime}$, respectively. 
We now discuss how we parametrize $\eta(V)$. Our model implies that in steady state,

$$
\frac{\pi \mu_{z^{*}}}{\beta}=R,
$$

where a variable without a time subscript denotes its non-stochastic steady state value. In addition, the first order condition for $Q_{t}$ is:

$$
R_{t}=1+\eta^{\prime}\left(\frac{P_{t} C_{t}}{Q_{t}}\right)\left(\frac{P_{t} C_{t}}{Q_{t}}\right)^{2} .
$$

Let $\epsilon_{t}$ denote the interest semi-elasticity of money demand:

$$
\epsilon_{t} \equiv-\frac{100 \times d \log \left(\frac{Q_{t}}{P_{t}}\right)}{400 \times d R_{t}} .
$$

Denote the curvature of $\eta$ by $\varphi$ :

$$
\varphi=\frac{\eta^{\prime \prime} V}{\eta^{\prime}} .
$$

Then, the first order condition for $Q_{t}$ implies that the interest semi-elasticity of money demand in steady state is:

$$
\epsilon=\frac{1}{4}\left(\frac{1}{R-1}\right)\left(\frac{1}{2+\varphi}\right) .
$$

We parameterize $\eta(\cdot)$ indirectly using values for $\epsilon, V$ and $\eta$.

The remaining terms in (2.12) pertain to the household's capital related income. The services of capital, $K_{t}$, are related to stock of physical capital, $\bar{K}_{t}$, by

$$
K_{t}=u_{t} \bar{K}_{t} .
$$

The term $P_{t} r_{t}^{k} u_{t} \bar{K}_{t}$ represents the household's earnings from supplying capital services. The function $a\left(u_{t}\right) \bar{K}_{t}$ denotes the cost, in investment goods, of setting the utilization rate to $u_{t}$. We assume $a\left(u_{t}\right)$ is increasing and convex. These assumptions capture the idea that the more intensely the stock of capital is utilized, the higher are maintenance costs in terms of investment goods. We assume that $u_{t}=1$ in steady state and $a(1)=0$. To implement our log-linear solution method, we must specify a value for the curvature of $a$ in steady state, $\sigma_{a}=a^{\prime \prime}(1) / a^{\prime}(1) \geq 0$. Although the steady state of the model does not depend on the value of $\sigma_{a}$, the dynamics do. Given our solution procedure, we do not need to specify any other features of the function $a$.

The household's stock of physical capital evolves according to:

$$
\bar{K}_{t+1}=(1-\delta) \bar{K}_{t}+F\left(I_{t}, I_{t-1}\right),
$$

where $\delta$ denotes the physical rate of depreciation and $I_{t}$ denotes time $t$ investment goods. The function $F$ summarizes the technology that transforms current and past investment into 
installed capital for use in the following period. As in Christiano et al (2005), we assume that investment adjustment costs are given by:

$$
F\left(I_{t}, I_{t-1}\right)=\left(1-S\left(\frac{I_{t}}{I_{t-1}}\right)\right) I_{t} .
$$

The function $S$ is assumed to be increasing, convex and satisfies: $S=S^{\prime}=0$, and $S^{\prime \prime}>0$, in steady state. Although the steady state of the model does not depend on the value of $S^{\prime \prime}$, the dynamics do. Given our solution procedure, we do not need to specify any other features of the function $S$.

Note that in households' budget constraint, the price of investment goods relative to consumption goods is given by $\Upsilon_{t}^{-1}$ which we assume is an exogenous stochastic process. One way to rationalize this assumption is that agents transform final goods into investment goods using a linear technology with slope $\Upsilon_{t}$. This rationalization also underlies why we refer to $\Upsilon_{t}$ as capital embodied technological progress.

\subsubsection{The Wage Decision}

As in Erceg, Henderson, and Levin (2000), we assume that the $j^{\text {th }}$ household is a monopoly supplier of a differentiated labor service, $h_{j t}$. It sells this service to a representative, competitive firm that transforms it into an aggregate labor input, $L_{t}$, using the technology:

$$
H_{t}=\left[\int_{0}^{1} h_{j, t}^{\frac{1}{\lambda_{w}}} d j\right]^{\lambda_{w}}, 1 \leq \lambda_{w}<\infty .
$$

The demand curve for $h_{j, t}$ is given by:

$$
h_{j, t}=\left(\frac{W_{t}}{W_{j t}}\right)^{\frac{\lambda_{w}}{\lambda_{w}-1}} H_{t}
$$

Here, $W_{t}$ is the aggregate wage rate, i.e., the nominal price of $H_{t}$. It is straightforward to show that $W_{t}$ is related to $W_{j, t}$ via the relationship:

$$
W_{t}=\left[\int_{0}^{1}\left(W_{j, t}\right)^{\frac{1}{1-\lambda w}} d j\right]^{1-\lambda_{w}}
$$

The household takes $H_{t}$ and $W_{t}$ as given.

Households set their nominal wage according to a variant of the mechanism by which intermediate good firms set prices. In each period, a household faces a constant probability, $1-\xi_{w}$, of being able to re-optimize its nominal wage. The ability to re-optimize is independent across households and time. If a household cannot re-optimize its wage at time $t$, it sets $W_{j t}$ according to:

$$
W_{j, t}=\pi_{t-1} \mu_{z^{*}} W_{j, t-1} .
$$

The presence of $\mu_{z^{*}}$ in (2.25) implies that there are no distortions from wage dispersion along the steady state growth path. 


\subsubsection{Monetary and Fiscal Policy}

We adopt the following specification of monetary policy:

$$
\hat{x}_{t}=\hat{x}_{z t}+\hat{x}_{\Upsilon t}+\hat{x}_{M t} .
$$

Here $x_{t}$ represents the gross growth rate of money, $M_{t} / M_{t-1}$. We assume that

$$
\begin{aligned}
\hat{x}_{M, t} & =\rho_{x M} \hat{x}_{M, t-1}+\varepsilon_{M, t} \\
\hat{x}_{z, t} & =\rho_{x z} \hat{x}_{z, t-1}+c_{z} \varepsilon_{z, t}+c_{z}^{p} \varepsilon_{z, t-1} \\
\hat{x}_{\Upsilon, t} & =\rho_{x \Upsilon} \hat{x}_{\Upsilon, t-1}+c_{\Upsilon} \varepsilon_{\Upsilon, t}+c_{\Upsilon}^{p} \varepsilon_{\Upsilon, t-1}
\end{aligned}
$$

Here, $\varepsilon_{M, t}$ represents a shock to monetary policy. We denote the standard deviation of $\varepsilon_{M, t}$ by $\sigma_{M}$. The dynamic response of $\hat{x}_{M, t}$ to $\varepsilon_{M, t}$ is characterized by a first order autoregression, so that $\rho_{x M}^{j}$ is the response of $E_{t} \hat{x}_{t+j}$ to a one-unit time $t$ monetary policy shock. The term $\hat{x}_{z, t}$ captures the response of monetary policy to an innovation in neutral technology, $\varepsilon_{z, t}$. We assume that $\hat{x}_{z, t}$ is characterized by an $\operatorname{ARMA}(1,1)$ process. The term, $\hat{x}_{\Upsilon, t}$, captures the response of monetary policy to an innovation in capital embodied technology, $\varepsilon_{\Upsilon, t}$. We assume that $\hat{x}_{\Upsilon, t}$ is also characterized by an ARMA $(1,1)$ process.

Finally, we assume that the government adjusts lump sum taxes to ensure that its intertemporal budget constraint holds.

\subsubsection{Loan Market Clearing, Final Goods Market Clearing and Equilibrium}

Financial intermediaries receive $M_{t}-Q_{t}+\left(x_{t}-1\right) M_{t}$ from the household. Our notation reflects the equilibrium condition, $M_{t}^{a}=M_{t}$. Financial intermediaries lend all of their money to intermediate good firms, which use the funds to pay labor wages. Loan market clearing requires that:

$$
W_{t} H_{t}=x_{t} M_{t}-Q_{t}
$$

The aggregate resource constraint is:

$$
\left(1+\eta\left(V_{t}\right)\right) C_{t}+\Upsilon_{t}^{-1}\left[I_{t}+a\left(u_{t}\right) \bar{K}_{t}\right] \leq Y_{t}
$$

We adopt a standard sequence-of-markets equilibrium concept. In an appendix available upon request, we discuss our computational strategy for approximating that equilibrium. This strategy involves taking a linear approximation about the non-stochastic steady state of the economy and using the solution method discussed in Christiano (2002). 


\subsection{The Firm - Specific Capital Model}

In this model, firms own their own capital. The capital that the firm begins the period with cannot be adjusted during the period. The firm can change its stock of capital by varying its rate of investment. In all other respects the problem of intermediate good firms is the same as before. In particular, they face the same demand curve, (2.2), production technology, (2.4)-(2.8), and Calvo-style pricing frictions, including the updating rule given by (2.9).

The technology for accumulating physical capital by intermediate good firm $i$ is given by

$$
F\left(I_{t}(i), I_{t-1}(i)\right)=\left(1-S\left(\frac{I_{t}(i)}{I_{t-1}(i)}\right)\right) I_{t}(i),
$$

and

$$
\bar{K}_{t+1}(i)=(1-\delta) \bar{K}_{t}(i)+F\left(I_{t}(i), I_{t-1}(i)\right) .
$$

The present discounted value of the $i^{\text {th }}$ intermediate good's net cash flow is given by:

$E_{t} \sum_{j=0}^{\infty} \beta^{j} v_{t+j}\left\{P_{t+j}(i) y_{t+j}(i)-P_{t+j} R_{t+j} w_{t+j}(i) h_{t}(i)-P_{t+j} \Upsilon_{t+j}^{-1}\left[I_{t+j}(i)+a\left(u_{t+j}(i)\right) \bar{K}(i)_{t+j}\right]\right\}$.

Time $t$ net cash flow equals sales, less labor costs (inclusive of interest charges) less the costs associated with capital utilization and capital accumulation.

The sequence of events as it pertains to the $i^{\text {th }}$ firm is as follows. At the beginning of period $t$, the firm has a stock of physical capital, $\bar{K}_{t}(i)$, which it takes as given. After observing the technology shocks, the firm sets its price, $P_{t}(i)$, subject to the Calvo-style frictions described above. The firm also makes its investment and capital utilization decisions, $I_{t}(i)$ and $u_{t}(i)$, respectively. The time $t$ monetary policy shock then occurs and the demand for the firm's product is realized. The firm then purchases labor to satisfy the demand for its output. Subject to these timing and other constraints, the problem of the firm is to choose prices, employment, the level of investment and utilization to maximize net discounted cash flow.

\subsection{Implications for Inflation}

The equations which characterize equilibrium for the homogenous and firm-specific capital model are identical except for the equation which characterizes aggregate inflation dynamics. This equation is of the form:

$$
\Delta \hat{\pi}_{t}=E\left[\beta \Delta \hat{\pi}_{t+1}+\gamma \hat{s}_{t} \mid \Omega_{t}\right]
$$

where

$$
\gamma=\frac{\left(1-\xi_{p}\right)\left(1-\beta \xi_{p}\right)}{\xi_{p}} \chi
$$


and $\Delta$ is the first difference operator. The information set $\Omega_{t}$ includes the current realization of the technology shocks, but not the current realization of the innovation to monetary policy. The variable $s_{t}$ denotes the economy-wide average marginal cost of production, in units of the final good.

In Altig et al. (2004) we establish the following ${ }^{12}$ :

Proposition 1 (i) In the homogeneous capital model, $\chi=1$; (ii) In the firm-specific capital model, $\chi$ is a particular non-linear function of the parameters of the model.

We parameterize the firm-specific and homogeneous capital model in terms of $\gamma$, rather than $\xi_{p}$. Consequently, the list of parameters for the two models remains identical. Given values for these parameters, the two models are observationally equivalent with respect to aggregate prices and quantities. This means that we do not need to take a stand on which version of the model we are working with at the estimation stage of our analysis.

\section{Econometric Methodology}

To estimate and evaluate the empirical plausibility of our model, we employ a variant of the limited information strategy used in Christiano et al. (2005) (see also Rotemberg and Woodford (1997)). The idea is to impose a subset of the assumptions made in our equilibrium model to estimate the impulse response functions of 10 key macroeconomic variables to neutral technology shocks, capital embodied technology shocks and monetary policy shocks. We then choose model parameters to minimize the distance between the estimated impulse response functions and the analogous objects in our model.

To discuss our econometric methodology, we define the ten dimensional vector, $Y_{t}$ :

$$
\underbrace{Y_{t}}_{10 \times 1}=\left(\begin{array}{c}
\Delta \ln \left(\text { relative price of investment }_{t}\right) \\
\Delta \ln \left(G D P_{t} / \text { Hours }_{t}\right) \\
\Delta \ln \left(G D P \text { deflator }_{t}\right) \\
\text { Capacity } \text { Utilization }_{t} \\
\ln \left(\text { Hours }_{t}\right) \\
\ln \left(G D P_{t} / \text { Hours }_{t}\right)-\ln \left(W_{t} / P_{t}\right) \\
\ln \left(C_{t} / G D P_{t}\right) \\
\ln \left(I_{t} / G D P_{t}\right) \\
\text { Federal Funds Rate }_{t} \\
\ln \left(G D P \text { deflator }_{t}\right)+\ln \left(G D P_{t}\right)-\ln \left(M Z M_{t}\right)
\end{array}\right)=\left(\begin{array}{c}
\underbrace{\Delta p_{I t}}_{1 \times 1} \\
\underbrace{\Delta a_{t}}_{1 \times 1} \\
\underbrace{Y_{1 t}}_{6 \times 1} \\
\underbrace{R_{t}}_{1 \times 1} \\
\underbrace{Y_{2 t}}_{1 \times 1}
\end{array}\right)
$$

We embed our identifying assumptions as restrictions on the parameters of the following reduced form VAR:

\footnotetext{
${ }^{12}$ See Christiano (2004) for a discussion of the solution to firm-specific capital models in simpler settings.
} 


$$
\begin{aligned}
Y_{t} & =\alpha+B(L) Y_{t-1}+u_{t}, \\
E u_{t} u_{t}^{\prime} & =V
\end{aligned}
$$

where $B(L)$ is a $p^{t h}$-ordered polynomial in the lag operator, $L$. The "fundamental" economic shocks, $\varepsilon_{t}$, are related to $u_{t}$ as follows:

$$
u_{t}=C \varepsilon_{t}, E \varepsilon_{t} \varepsilon_{t}^{\prime}=I
$$

where $C$ is a square matrix and $I$ is the identity matrix. We require $B(L)$ and the $i^{\text {th }}$ column of $C, C_{i}$, to calculate the dynamic response of $Y_{t}$ to a disturbance in the $i^{\text {th }}$ fundamental shock, $\varepsilon_{i t}$,

According to our economic model, the variables in $Y_{t}$, defined in (3.1), are stationary stochastic processes. We partition $\varepsilon_{t}$ conformably with the partitioning of $Y_{t}$ :

$$
\varepsilon_{t}=(\underbrace{\varepsilon_{\Upsilon, t}}_{1 \times 1} \underbrace{\varepsilon_{z, t}}_{1 \times 1} \underbrace{\varepsilon_{1 t}^{\prime}}_{1 \times 6} \underbrace{\varepsilon_{M, t}}_{1 \times 1} \underbrace{\varepsilon_{2 t}}_{1 \times 1})^{\prime} .
$$

Here, $\varepsilon_{z, t}$ is the innovation to a neutral technology shock, $\varepsilon_{\Upsilon, t}$ is the innovation in capitalembodied technology, and $\varepsilon_{M, t}$ is the monetary policy shock.

\subsection{Identification of Impulse Responses}

To identify the monetary policy shock, we use the recursive approach of Christiano, Eichenbaum, and Evans (1999). Specifically, we assume that policy makers set the interest rate so that the following rule is satisfied:

$$
R_{t}=f\left(\Omega_{t}\right)+\omega \varepsilon_{M, t},
$$

where $\varepsilon_{M, t}$ is the monetary policy shock with unit variance and $\omega$ is a positive coefficient. We interpret (3.5) as a reduced form Taylor rule. To ensure identification of the monetary policy shock, we assume $f$ is linear, $\Omega_{t}$ contains $Y_{t-1}, \ldots, Y_{t-q}$ and the only date $t$ variables in $\Omega_{t}$ are $\left\{\Delta a_{t}, \Delta p_{I t}, Y_{1 t}\right\}$. Finally, we assume that $\varepsilon_{M t}$ is orthogonal to $\Omega_{t}$.

To identify the shocks to technology, we adopt the strategy used by Fisher (2003) to identify neutral and capital embodied shocks to technology. We assume that innovations to technology (both neutral and capital embodied) are the only shocks which affect the level of labor productivity in the long run. In addition, we assume that capital embodied technology shocks are the only shocks that affect the price of investment goods relative to consumption goods in the long run. These assumptions are satisfied in our model.

To compute the responses of $Y_{t}$ to $\varepsilon_{\Upsilon, t}, \varepsilon_{z, t}$, and $\varepsilon_{M, t}$, we require estimates of the parameters in $B(L)$, as well as the $1^{\text {st }}, 2^{\text {nd }}$ and $9^{\text {th }}$ columns of $C$. We obtain these estimates using 
a suitably modified variant of the instrumental variables strategy proposed by Shapiro and Watson (1988). The structural form representation of our VAR system is:

$$
A_{0} Y_{t}=A(L) Y_{t-1}+\varepsilon_{t}
$$

The parameters of the reduced form are related to those of the structural form by:

$$
C=A_{0}^{-1}, B(L)=A_{0}^{-1} A(L) \text {. }
$$

We obtain impulse responses by first estimating the parameters of the structural form and executing (3.7), and then simulating the reduced form, (3.2). The assumptions we make to identity the monetary policy shock impose zero restrictions on $A_{0}$. In particular, the entries in the first nine rows of the tenth column of $A_{0}$ and the first eight rows of the ninth column of $A_{0}$ are zero. In all cases but one, the parameters of the rows of (3.6) are estimated by instrumental variables. The ninth equation, which corresponds to (3.5), is the exception and it is estimated by ordinary least squares. The matrix, $C$, and the shocks, $\varepsilon_{t}$, are identified up to a particular transformation. To see this, define the ten by ten orthonormal matrix $W$ by:

$$
W=\left[\begin{array}{ccc}
I & 0 & 0 \\
2 \times 2 & 2 \times 6 & 2 \times 2 \\
0 & w & 0 \\
6 \times 2 & 6 \times 6 & 6 \times 2 \\
0 & 0 & I \\
2 \times 2 & 2 \times 6 & 2 \times 2
\end{array}\right]
$$

where $w$ is orthonormal, i.e., $w w^{\prime}=w^{\prime} w=I$, the $6 \times 6$ identity matrix. Also, let $\hat{C}$ denote our estimate of $C$ and let $\hat{\varepsilon}_{t}$ denote our fitted disturbances. Then the matrix, $\tilde{C}$ and disturbances $\tilde{\varepsilon}_{t}$, also satisfy our identification assumptions and fit the data equally well, where $\tilde{C} \equiv \hat{C} W^{\prime}$ and $\tilde{\varepsilon}_{t} \equiv W \hat{\varepsilon}_{t}$. Here, $W$ is an arbitrary orthonormal matrix satisfying (3.8). As a result, the individual components of $\varepsilon_{1 t}$ and their dynamic effects on $Y_{t}$ are not identified. However, the other shocks in $\varepsilon_{t}$ are uniquely identified, as are all the columns of $C$, apart from columns 3 through $8 .{ }^{13}$ For additional details of our VAR estimation strategy, see Altig, Christiano, Eichenbaum, and Linde (2003), the technical appendix to this paper.

Our VAR analysis decomposes the time series into two orthogonal components: a part that is driven by our identified shocks and a part that is driven by the shocks we have not identified. Using (3.4) and the expression for the reduced form VAR disturbance, $u_{t}$, in (3.3) we write:

$$
u_{t}=C \varepsilon_{t}=C_{1}\left(\begin{array}{c}
\varepsilon_{\Upsilon, t} \\
\varepsilon_{z, t} \\
\varepsilon_{M_{t}}
\end{array}\right)+C_{2}\left(\begin{array}{c}
\varepsilon_{1 t} \\
\varepsilon_{2, t}
\end{array}\right)
$$

\footnotetext{
${ }^{13}$ The last shock, $\varepsilon_{2 t}$, in our system is also uniquely identified as a result of the identification assumptions we place on the policy and technology shocks. We treat this as a curiosity. We have not explored what shock or combination of shocks, $\varepsilon_{2 t}$ might correspond to.
} 
where $C_{1}$ is composed of the first, second and ninth columns of $C$, and $C_{2}$ is composed of the other columns. Let $Y_{t}^{\text {Identified }}$ and $Y_{t}^{\text {Other }}$ be stochastic processes with the following time series representations:

$$
\begin{aligned}
Y_{t}^{\text {Identified }} & =B(L) Y_{t-1}^{\text {Identified }}+C_{1}\left(\begin{array}{c}
\varepsilon_{\Upsilon, t} \\
\varepsilon_{z, t} \\
\varepsilon_{M_{t}}
\end{array}\right) \\
Y_{t}^{\text {Other }} & =B(L) Y_{t-1}^{\text {Other }}+C_{2}\left(\begin{array}{c}
\varepsilon_{1 t} \\
\varepsilon_{2, t}
\end{array}\right) .
\end{aligned}
$$

Our VAR analysis implies that the data, $Y_{t}$, is the sum of these two orthogonal stochastic processes:

$$
Y_{t}=Y_{t}^{\text {Identified }}+Y_{t}^{\text {Other }} .
$$

Our model estimation exercise fits a model to the data, $Y_{t}^{\text {Identified }}$, taking into account that the actual data, $Y_{t}$, is composed not just of $Y_{t}^{\text {Identified }}$, but also $Y_{t}^{\text {Other }}$.

\subsection{Estimating the Parameters of the Equilibrium Model}

Let $\zeta$ denote the model parameters that we estimate and let $\Psi(\zeta)$ denote the mapping from $\zeta$ to the model impulse response functions. We denote by $\hat{\Psi}$ the corresponding estimates obtained by the strategy described above. We include the first 20 elements of each response function, excluding those that are zero by assumption. Our estimator of $\zeta$ is the solution to:

$$
\hat{\zeta}=\arg \min _{\zeta}(\hat{\Psi}-\Psi(\zeta))^{\prime} V^{-1}(\hat{\Psi}-\Psi(\zeta))
$$

Here, $V$ is a diagonal matrix with the sample variances of the $\hat{\Psi}$ 's along the diagonal. These variances are the ones that were used to construct the confidence intervals displayed in Figures 1-3. With this choice of $V, \hat{\zeta}$ is the value of $\zeta$ which ensures that $\Psi(\zeta)$ lies as much as possible inside the confidence intervals in Figures 1-3. We compute standard errors for $\hat{\zeta}$ using the delta-function method. ${ }^{14}$

\footnotetext{
${ }^{14}$ Let the criterion in $(3.12)$ be denoted $L(\zeta, \hat{\Psi}) \equiv(\hat{\Psi}-\Psi(\zeta))^{\prime} V^{-1}(\hat{\Psi}-\Psi(\zeta))$, so that $L_{1}(\hat{\zeta}, \hat{\Psi})=0$. Denote the mapping in (3.12) by $\hat{\zeta}=f(\hat{\Psi})$. To obtain the sampling variance of the estimator, $\hat{\zeta}$, as a function of the sampling variance of $\hat{\Psi}$, the delta-function method approximates $f(\hat{\Psi})$ by its linear expansion about the true value of $\Psi, \Psi^{0}$. That is, $f(\hat{\Psi}) \approx f\left(\Psi^{0}\right)+f^{\prime}\left(\Psi^{0}\right)\left(\hat{\Psi}-\Psi^{0}\right)$. Here, $f\left(\Psi^{0}\right)=\zeta^{0}$, where $\zeta^{0}$ is the true value of $\zeta$, by the consistency of our estimator. Then, $\sqrt{T}\left(\hat{\zeta}_{T}-\zeta^{0}\right)$ is asymptotically Normally distributed with mean zero and variance $f^{\prime}\left(\Psi^{0}\right) W f^{\prime}\left(\Psi^{0}\right)^{T}$, where the superscript $T$ indicates the transposition operator, and $W$ is the asymptotic variance-covariance matrix of $\sqrt{T}(\hat{\Psi}-\Psi)$. We use the implicit function theorem to approximate $f^{\prime}\left(\Psi^{0}\right)$ by $-L_{11}\left(\zeta^{0}, \Psi^{0}\right)^{-1} L_{12}\left(\zeta^{0}, \Psi^{0}\right)$. This discussion has assumed that $V$ is not random. In practice, we use the sample-based object discussed in the text. In addition, $W$ is replaced by its sample estimate, as are $\zeta^{0}$ and $\Psi^{0}$ in the expression for $f^{\prime}$. As noted in the text, $V$ is a diagonal matrix composed of the diagonal elements of $W$.
} 


\section{Estimation Results Based on Identified Vector Autoregressions}

In this section we describe the dynamic response of the economy to monetary policy shocks, neutral technology shocks and capital embodied shocks. In addition, we discuss the quantitative contribution of these shocks to the cyclical fluctuations in aggregate economic activity. In the first subsection we describe the data used in the analysis. In the second and third subsections we discuss the impulse response functions and the importance of the shocks to aggregate fluctuations.

\subsection{Data}

With the exception of the price of investment and of monetary transactions balances, all data were taken from the DRI Basic Economics Database. ${ }^{15}$ The price of investment corresponds to the 'total investment' series constructed and used in Fisher (2003). ${ }^{16}$ Our measure of transactions balances, $M Z M$, was obtained from the Federal Reserve Bank of St. Louis' online database. Our data are quarterly and the sample period is $1959 \mathrm{II}-2001 \mathrm{IV} .{ }^{17}$

We work with the monetary aggregate, $M Z M$, for the following reasons. First, $M Z M$ is constructed to be a measure of transactions balances, so it is a natural empirical counterpart to our model variable, $Q_{t}$. Second, our statistical procedure requires that the velocity of money is stationary. The velocity of $M Z M$ is reasonably characterized as being stationary. However the stationarity assumption is more problematic for the velocity of monetary aggregates like the base, $M 1$ and $M 2$ are not stationary.

\footnotetext{
${ }^{15}$ This data base is available online at Northwestern University. Nominal gross output is measured by $G D P$, real gross output is measured by $G D P Q$ (real, chain-weighted output). Nominal investment is $G C D$ (household consumption of durables) plus GPI (gross private domestic investment). Nominal consumption is measured by $G C N$ (nondurables) plus GCS (services) plus GGE (government expenditures). Our MZM measure of money was obtained by splicing the Federal Reserve Bank of St. Louis' measure, 'M2 minus' (this is M2, less small time deposits and has mnemonic M2MSL) with their MZM measure (mnemonic MZMSL). Both data series are monthly, and were converted to quarterly using end-of-quarter observations. The splice was accomplished by replacing the M2 minus data with MZM beginning in 1974. No scaling was done to implement the splice since the two series are essentially the same in 1974. These variables were converted into per capita terms by $P 16$, a measure of the US population over age 16. A measure of the aggregate price index was obtained from the ratio of nominal to real output, $G D P / G D P Q$. Capacity utilization is measured by IPXMCA the manufacturing industry's capacity index (there is a measure for total industry, IPX, but it only starts in 1967). The interest rate is measured by the federal funds rate, $F Y F F$. Hours worked is measured by LBMNU (Nonfarm business hours). Hours were converted to per capita terms using our population measure. Nominal wages are measured by LBCPU, (nominal hourly non-farm business compensation). This was converted to real terms by dividing by the aggregate price index.

${ }^{16}$ We also re-estimated the VAR and the structural model using as our measure of hours and productivity, private business hours and business sector productivity, respectively. In these estimation runs, we measure consumption and output as private sector consumption and private sector output, respectively. Taking sampling uncertainty, we find that our results are robust to these alternatives data measures.

${ }^{17}$ The estimation period for the vector autoregression drops the first 4 quarters, to accommodate the 4 lags.
} 


\subsection{Estimated Impulse Response Functions}

In this subsection we discuss our estimates of the dynamic response of $Y_{t}$ to monetary policy and technology shocks. To obtain these estimates we set $q$, the number of lags in the VAR, to 4. Various indicators suggest that this value of $q$ is large enough to adequately capture the dynamics in the data. For example, the Akaike, Hannan-Quinn and Schwartz criteria support a choice of $q=2,1,1$, respectively. ${ }^{18}$ We also compute the multivariate Portmanteau (Q) statistic to test the null hypothesis of zero serial correlation up to lag $n$ in the VAR disturbances. We consider $n=4,6,8,10$. The test statistics are, respectively, $Q=167,350,552,796$. Using conventional asymptotic sampling theory, these $Q$ statistics all have a $p$-value very close to zero, indicating a rejection of the null hypothesis. However, we find evidence that the asymptotic sampling theory rejects the null hypothesis too often. When we simulate the $Q$ statistic using repeated artificial data sets generated from our estimated VAR, we find that the $p$-values of our $Q$ statistics are 89, 92, 83, and 39 percent, respectively. For these calculations, each artificial data set is of length equal to that of our actual sample, and is generated by bootstrap sampling from the fitted disturbances in our estimated VAR. On this basis we do not reject the null hypothesis that the disturbance terms in a VAR with $q=4$ are serially uncorrelated.

Figure 1 displays the response of the variables in our analysis to a one standard deviation monetary policy shock (roughly 60 basis points). In each case, there is a solid line in the center of a gray area. The gray area represents a 95 percent confidence interval, and the solid line represents the point estimates. ${ }^{19}$ Except for inflation and the interest rate, all variables are expressed in percent terms. So, for example, the peak response of output is a little over 0.2 percent. The Federal Funds rate is expressed in units of percentage points, at an annual rate. Inflation is expressed in units of percentage points, at a quarterly rate.

Six features of Figure 1 are worth noting. First, the effect of a policy shock on the money growth rate and the interest rate is completed within roughly one year. The other variables respond over a longer period of time. Second, there is a significant liquidity effect, i.e. the interest rate and money growth move in opposite directions after a policy shock. Third, after an initial fall, inflation rises before reaching its peak response in roughly two years. Fourth, output, consumption, investment, hours worked and capacity utilization all display hump-shaped responses, which peak after roughly one year. Fifth, velocity co-moves with the interest rate. Both fall in response to a monetary policy shock, and then rise. Finally,

\footnotetext{
${ }^{18}$ See Bierens (2004) for the formulas used and for a discussion of the asymptotic properties of the lag length selection criteria.

${ }^{19}$ The confidence intervals are symmetric about our point estimates. They are obtained by adding and subtracting 1.96 times our estimate of the standard errors of the coefficients in the impulse response functions. These standard errors were computed by bootstrap simulation of the estimated model.
} 
the real wage and the price of investment do not respond significantly to a monetary policy shock.

Figure 2 displays the response of the variables in our analysis to a positive, one standard deviation shock in neutral technology, $e_{z t}$. By construction, the impact of this technology shock on output, labor productivity, consumption, investment and the real wage can be permanent. Because the roots of our estimated VAR are stable, the impact of a neutral technology shock on the variables whose levels appear in $Y_{t}$ must be temporary. These variables are the Federal Funds rate, capacity utilization, hours worked and inflation.

We note that a positive, neutral technology shock leads to a persistent rise in output with a peak rise of roughly 0.6 percent over the period displayed. In addition, hours worked, investment and consumption display strong, statistically significant responses to the technology shock. Capacity utilization also rises but the response is not statistically significant. Both velocity and the price of investment show marginally significant drops in response to the shock. Finally notice that a neutral technology shock leads to a sharp, persistent fall in the inflation rate. ${ }^{20}$. Overall, these effects are broadly consistent with what a student of real business cycle models might expect. The rise in hours worked contrasts with the findings in other recent papers which make the same identifying assumptions about a neutral technology shock as we do here (see for example Gali (1999) and Francis and Ramey (2002)). However, these papers argue that hours worked fall in the wake of a positive, neutral technology shock. Christiano, Eichenbaum, and Vigfusson (2003a, 2003b) argue that the reason for this difference is that Gali (1999) and Francis and Ramey (2001) work with the first difference rather than the level of hours worked. Christiano, Eichenbaum, and Vigfusson (2003a, 2003b) argue on statistical grounds that first differencing hours worked amounts to a specification error, and that the quantitative findings in those papers can be explained by this error. ${ }^{21}$

Figure 3 displays the response of the variables in our analysis to a one standard deviation positive capital embodied technology shock, $e_{\Upsilon, t}$. This shock leads to marginally significant rises in output, hours worked and the federal funds rate. In contrast, investment responds strongly to the shock in $e_{\Upsilon, t}$, with an initial peak response of over 2 percent. In addition, the shock leads to an initial fall in the price of investment of roughly 0.3 percent, followed by an ongoing significant decline.

\footnotetext{
${ }^{20}$ Alves (2004) also finds that inflation drops after a positive neutral technology shocks using data for non-U.S. G7 countries

${ }^{21}$ Christiano, Eichenbaum and Vigfusson (2003a) also argue against findings that hours worked fall after a positive technology shock, based on analyses in which hours worked is detrended using a quadratic trend.
} 


\subsection{The Contribution of Monetary Policy and Technology Shocks to Aggregate Fluctuations}

We now briefly discuss the contribution of monetary policy and technology shocks to the cyclical fluctuations in economic activity. Table 1 summarizes the contribution of the three shocks to the variables in our analysis. We define business cycle frequencies as the components of a time series with periods of 8 to 32 quarters. The columns in Table 1 report the fraction of the variance in the cyclical frequencies accounted for by our three shocks. Each row corresponds to a different variable. We calculate the fractions as follows. Let $f^{i}(\omega)$ denote the spectral density at frequency $\omega$ of a given variable, when only shock $i$ is active. That is, the variance of all shocks in $\varepsilon_{t}$, apart from the $i^{\text {th }}$, are set to zero and the variance of the $i^{\text {th }}$ shock in $\varepsilon_{t}$ is set to unity. Let $f(\omega)$ denote the corresponding spectral density when the variance of each element of $\varepsilon_{t}$ is set to unity. The contribution of shock $i$ to variance in the business cycle frequencies is then defined as:

$$
\frac{\int_{\omega_{1}}^{\omega_{2}} f^{i}(\omega) d \omega}{\int_{\omega_{1}}^{\omega_{2}} f(\omega) d \omega}, \omega_{1}=\frac{2 \pi}{32}, \omega_{2}=\frac{2 \pi}{8} .
$$

We compute the spectral densities $f$ and $f^{i}$ using our estimated VAR. ${ }^{22}$ Numbers in parentheses are the standard errors, which we estimate by bootstrap methods. Finally, the fraction of the variance accounted for by all three shocks is just the sum of the individual fractions of the variance.

Table 1 shows that the three shocks together account for a substantial portion of the cyclical variance in the aggregate quantities. For example, they account for nearly 50 percent of the variation in aggregate output, with the three shocks contributing roughly the same amount. Interestingly, the shocks account for very little of the cyclical variation in real wages.

\section{Estimation Results for the Equilibrium Model}

In this section we discuss the estimated parameter values. In addition, we assess the ability of the estimated model to account for the impulse response functions discussed in Section 4.

\footnotetext{
${ }^{22}$ We found that the analog statistics computed using the Hodrick-Prescott filter yielded essentially the same results. We computed this as follows:

$$
\frac{\int_{0}^{\pi} g(\omega) f^{i}(\omega) d \omega}{\int_{0}^{\pi} g(\omega) f(\omega) d \omega}
$$
}

where $g(\omega)$ is the frequency-domain representation of the Hodrick-Prescott filter with $\lambda=1600$. 


\subsection{Benchmark Parameter Estimates}

We partition the parameters of the model into three groups. The first group of parameters, $\zeta_{1}$, are:

$$
\zeta_{1}=\left[\beta, \alpha, \delta, \phi, \psi_{L}, \lambda_{w}, \mu_{\Upsilon}, \mu_{z}, x, V, \eta\right]
$$

The second of parameters, $\zeta_{2}$, pertain to the 'non-stochastic part' of the model:

$$
\zeta_{2}=\left[\lambda_{f}, \xi_{w}, \gamma, \sigma_{a}, b, S^{\prime \prime}, \epsilon\right]
$$

The third set of parameters, $\zeta_{3}$, pertain to the stochastic part of the model:

$$
\zeta_{3}=\left[\rho_{x M}, \sigma_{M}, \rho_{\mu_{z}}, \sigma_{\mu_{z}}, \rho_{x z}, c_{z}, c_{z}^{p}, \rho_{\mu_{\Upsilon}}, \sigma_{\mu_{\Upsilon}}, \rho_{x \Upsilon}, c_{\Upsilon}, c_{\Upsilon}^{p}\right]
$$

The first two parameters in $\zeta_{3}$ characterize the monetary policy shock (see (2.26).) The next five parameters in $\zeta_{3}$ characterize the evolution of the disembodied technical shock, as well as the monetary policy response to that shock. The last five parameters are the analogous objects that correspond to the embodied shock to technology. In all, we have to estimate 19 parameters.

We estimate the values of $\zeta_{2}$ and $\zeta_{3}$ and set the values of $\zeta_{1}$ a priori. We assume $\beta=1.03^{-0.25}$, which implies a steady state annualized real interest rate of 3 percent. We set $\alpha=0.36$, which corresponds to a steady state share of capital income equal to roughly 36 percent. $^{23}$ We set $\delta=0.025$, which implies an annual rate of depreciation on capital equal to 10 percent. This value of $\delta$ is roughly equal to the estimate reported in Christiano and Eichenbaum (1992). The parameter, $\phi$, is set to guarantee that profits are zero in steady state. $^{24}$ As in Christiano et al. (2005), we set the parameter, $\lambda_{w}$, to 1.05 .

We set the parameter $\mu_{\Upsilon}$ to 1.0042. This corresponds to the negative of the average growth rate of the price of investment relative to the GDP deflator which fell at an annual average rate of 1.68 percent over our sample period. The steady state growth of real per capita GDP, $\mu_{y}$, is given by

$$
\mu_{y}=\left(\mu_{\Upsilon}\right)^{\frac{\alpha}{1-\alpha}} \mu_{z}
$$

The average growth rate of per capita GDP in our sample implies $\mu_{y}=1.0045$. Solving the previous equation for $\mu_{z}$ yields $\mu_{z}=1.00013$, which is the value of $\mu_{z}$ we use in our analysis. The average growth rate of money, $\mu_{x}$, was set equal to 1.017 . This value corresponds to the average quarterly growth rate of money $(M Z M)$ over our sample period.

\footnotetext{
${ }^{23}$ In our model, the steady state share of labor income in total output is $1-\alpha$. This result reflects our assumption that profits are zero in steady state.

${ }^{24}$ See Basu and Fernald (1994), Hall (1988), and Rotemberg and Woodford (1995) for a discussion of the relationship between $\phi$ and steady state profits.
} 
We set the parameters $V$ and $\eta$ to 0.45 and 0.036 , respectively. The value of $V$ corresponds to the average value of $P_{t} C_{t} / Q_{t}$ in our sample, where $Q_{t}$ is measured by $M Z M$. We chose $\eta$ so that in conjunction with the other parameter values of our model, the steady state value of $\eta C / Y$ is 0.025 . This corresponds to the percent of value-added in the finance, insurance and real estate industry (see Christiano, Motto, and Rostagno (2003)).

The row labeled 'benchmark' in Table 2 summarizes our point estimates of the parameters in the vector $\zeta_{1}$. Standard errors are reported in parentheses. The lower bound of unity is binding on $\lambda_{f}$. So we simply set $\lambda_{f}$ to 1.01 when we estimate the model. Our point estimate of $\xi_{w}$ implies that wage contracts are re-optimized, on average, once every 3.6 quarters. To interpret our point estimate of $\gamma$, we recall that in the homogeneous capital model, $\gamma=\left(1-\xi_{p}\right)\left(1-\beta \xi_{p}\right) / \xi_{p}$. So our point estimate of $\gamma$ implies a value of $\xi_{p}$ equal to 0.82 . This implies that firms re-optimize prices roughly every 5.6 quarters (see Table 4 ). This value is much larger than the value used by Golosov and Lucas (2003) who calibrate their model to micro data to ensure that the firms re-optimize prices on average once every 1.5 quarters.

Table 3 shows that if we adopt the assumption that capital is firm-specific, then our estimates imply that firms re-optimize prices on average once every 1.5 quarters. ${ }^{25}$ So the assumption that capital is firm-specific has a large impact on inference about the frequency at which firms re-optimize price.

To interpret the estimated value of $\sigma_{a}$, we consider the homogeneous capital model. Linearizing the household's first order condition for capital utilization about steady state yields:

$$
E\left\{\left(\frac{1}{\sigma_{a}} \hat{r}_{t}^{k}-\hat{u}_{t}\right) \mid \Omega_{t}\right\}=0 .
$$

According to this expression, $1 / \sigma_{a}$ is the elasticity of capital utilization with respect to the rental rate of capital. Our estimate of $\sigma_{a}$ is larger than the value estimated by Christiano et al. (2005) and indicates that it is relatively costly for firms to vary the utilization of capital.

Our point estimate of the habit parameter $b$ is 0.65 . This value is close to the point estimate of 0.66, reported in Christiano et al. (2005) and the value of 0.7 reported in Boldrin, Christiano, and Fisher (2001). The latter authors argue that the ability of standard general equilibrium models to account for the equity premium and other asset market statistics is considerably enhanced by the presence of habit formation in preferences.

We now discuss our point estimate of $S^{\prime \prime}$. Suppose we denote by $P_{k^{\prime}, t}$ the shadow price of one unit of $\bar{k}_{t+1}$, in terms of output. The variable $P_{k^{\prime}, t}$ is what the price of installed capital would be in the homogeneous capital model if there were a market for $\bar{k}_{t+1}$ at the beginning of period $t$. Proceeding as in Christiano et al. (2005), it is straightforward to show that the

\footnotetext{
${ }^{25}$ This number was obtained using the algorithm discussed in Altig et al. (2004).
} 
household's first order condition for investment implies:

$$
\hat{\imath}_{t}=\hat{\imath}_{t-1}+\frac{1}{S^{\prime \prime}} \sum_{j=0}^{\infty} \beta^{j} E\left[\hat{P}_{k^{\prime}, t+j} \mid \Omega_{t}\right] .
$$

According to this expression, $1 / S^{\prime \prime}$ is the elasticity of investment with respect to a one percent temporary increase in the current price of installed capital. Our point estimate implies that this elasticity is equal to 0.45 . The more persistent is the change in the price of capital, the larger is the percentage change in investment. This is because adjustment costs induce agents to be forward looking.

Our point estimate of $\epsilon$ is roughly unity. That is, a one percentage point increase in the annualized rate of interest induces a one percent decline in real transactions balances. This elasticity is smaller than what Lucas (1988) and others obtain when they estimate static money demand equations. We suspect that we obtain a lower value of $\epsilon$ than Lucas because our estimation criterion places relatively more weight on the high frequency movements in money and interest rates.

Table 3 reports the estimated values of the parameters pertaining to the stochastic part of the model. With these values, the laws of motion for the neutral and capital embodied technology shocks are:

$$
\begin{array}{r}
\hat{\mu}_{\Upsilon, t}=\underset{(0.22)}{0.24} \hat{\mu}_{\Upsilon, t-1}+\varepsilon_{\mu_{\Upsilon}, t}, 100 \times \sigma_{\mu_{\Upsilon}}=\underset{(0.04)}{0.30} \\
\hat{\mu}_{z, t}=\underset{(0.11)}{0.90} \hat{\mu}_{z, t-1}+\varepsilon_{\mu_{z}, t}, 100 \times \sigma_{\mu_{z}}=\underset{(0.04)}{0.07}
\end{array}
$$

Numbers in parentheses are standard errors. Our estimates imply that a one-standard deviation neutral technology shock drives $z_{t}$ up by 0.07 percent in the period of the shock and by $0.70(=0.07 /(1-0.90))$ percent in the long run. A one-standard deviation shock to embodied technology drives $\Upsilon_{t}$ up by 0.30 percent immediately and by 0.39 percent in the long run. Our estimates imply that shocks to neutral technology exhibit a high degree of serial correlation, while shocks to capital embodied technology do not.

It is interesting to compare our results for $\hat{\mu}_{z, t}$ with the ones reported in Prescott (1986), who estimates the properties of the technology shock process using the Solow residual. He finds that the shock is roughly a random walk and its growth rate has a standard deviation of roughly 1 percent. ${ }^{26}$ By contrast, our estimates imply that the unconditional standard deviation of the growth rate of neutral technology is roughly $0.16\left(=0.07 / \sqrt{\left(1-0.9^{2}\right)}\right)$

\footnotetext{
${ }^{26}$ Prescott (1986) actually reports a standard deviation of 0.763 percent. However, he adopts a different normalization for the technology shock than we do, by placing it in front of the production function. By assumption, the technology shock multiplies labor directly in the production and is taken to a power of labor's share. The value of labor's share that Prescott uses is 0.70 . When we translate Prescott's estimate into the one relevant for our normalization, we obtain $0.763 / .7 \approx 1$.
} 
percent. So we find that technology shocks are substantially less volatile but more persistent than those estimated by Prescott. In principle, these differences reflect two factors. First, from the perspective of our model, Prescott's estimate of technology confounds technology with variable capital utilization. Second, our analysis is based on different data sets and different identifying assumptions than Prescott's.

To understand the implications of our point estimates of the parameters of monetary policy, it is useful to consider the dotted lines in the bottom right-hand corners of Figures 1 through 3. There, we display the response of total money growth, i.e., $M_{t+1} / M_{t}$, to a monetary policy shock, a neutral technology, and a capital-embodied technology shock, respectively. We note a number of features of the estimated policy rules. First, the response of total money growth to a policy shock is short-lived. Second, total money growth responds positively and persistently, to a neutral technology shock. So, consistent with results in Gali, Lopez-Salido, and Valles (2003), we find that monetary policy is accommodative with respect to this shock. Third, total money growth also increases in a very persistent manner in response to a capital embodied technology shock.

\subsection{Properties of the Estimated Model}

The dotted lines in Figures 1 through 3 display the impulse response functions of the estimated model to monetary policy, neutral technology shocks and capital embodied shocks, respectively. Recall that the solid lines and the associated confidence intervals (the gray areas) pertain to the impulse response functions from the estimated, identified VARs.

\subsubsection{Response to a Monetary Policy Shock}

We begin by discussing the model's performance with respect to a monetary policy shock (see Figure 1). First, consistent with results in Christiano et al. (2005), the model does well at accounting for the dynamic response of the U.S. economy to a monetary policy shock. Most of the model responses lie within the two-standard deviation confidence interval computed from the data. We note that the model succeeds in accounting for the inertial response of inflation. Indeed, there is no noticeable rise in inflation until roughly a year after the policy shock. This is true even though firms in the firm-specific capital version of the model change prices on average once every 1.5 quarters.

Second, the model generates a very persistent response in output. The peak effect occurs roughly one year after the shock. The output response is positive for roughly two years. Third, the model accounts for the dynamic response of the interest rate to a monetary policy shock. Consistent with the data, an expansionary monetary policy shock induces a sharp decline in the interest rate which then returns to its pre-shock level within a year. 
We also note that according to the model, the growth rate of transactions balances rises for a brief period of time after the policy shock, but then quickly reverts to its pre-shock level. Figure 1 shows that the effects of a policy shock on aggregate economic activity persist beyond the effects on the policy variable itself. This property reflects the strong internal propagation mechanisms in the model.

Fourth, as in the data, the real wage remains essentially unaffected by the policy shock. Fifth, consumption, investment, and hours worked exhibit persistent, hump-shaped rises that are consistent with our VAR-based estimates. Sixth, consistent with the data, velocity falls after the expansionary policy shock. This fall reflects the rise in money demand associated with the initial fall in the interest rate. As the interest rate begins to move towards its pre-shock level and consumption rises, velocity also rises. However, these forces are not sufficiently strong to render the model consistent with the strong rise in velocity estimated from the identified VAR roughly five quarters after the policy shock. Seventh, by construction, the relative price of investment is not affected by a policy shock in the model. At least for the first two years after the policy shock, this lack of response is consistent with the response of the relative price of investment to a policy shock in the identified VAR. Finally, capacity utilization in the model rises by only a very small amount, and understates the rise that is estimated to occur in the data.

\subsubsection{Response to a Neutral Technology Shock}

We now discuss the model's performance with respect to a neutral technology shock (see Figure 2). First, the model does well at accounting for the dynamic response of the U.S. economy to a neutral technology shock. Specifically, the model accounts for the rise in aggregate output, hours worked, investment, consumption and the real wage. Second, the model understates the decline in velocity as well as the price of investment that occur after an expansionary neutral technology shock. Third, the model does not capture the fall in inflation that occurs after the shock. To some extent the small response of inflation in the model reflects the strong response of money growth after a neutral technology shock. This strong response of money growth is necessary to allow the model to capture the general rise in economic activity after the neutral technology shock. We reach this conclusion by computing the response of the model economy to a positive, neutral technology shock under the assumption that money growth remains unchanged from its steady state level. We find that absent monetary accommodation the output response is weak, hours worked fall and inflation declines. The estimation criterion prefers to match the output and employment response at the cost of doing less well with respect to the response of inflation.

Figure 2 shows that in terms of quantity variables, the model economy responds quali-

tatively to a neutral technology shock in the same way that a real business analyst would 
anticipate. Ironically, according to our model, the strong, short run expansionary effects of a neutral technology shock are due to the accommodative nature of monetary policy. This is consistent with the findings in Gali et al. (2002).

\subsubsection{Response to a Capital Embodied Technology Shock}

We now discuss the model's performance with respect to a capital embodied technology shock (see Figure 3). The model does very well in accounting for the response of the U.S. economy to this shock, except that it understates the rise in capacity utilization.

Figure 3 indicates that monetary policy is accommodative with respect to a capital embodied technology shock. To see the importance of monetary policy in the transmission of capital embodied technology shocks, we compute the response of the model economy to a positive, capital embodied neutral, technology shock under the assumption that money growth remains unchanged from its steady state level. We find that output and hours worked rise by much less, while inflation falls compared to what happens when monetary policy is accommodative. We conclude that, as with neutral technology shocks, monetary policy plays an important role in the transmission of capital embodied technology shocks.

\section{The Key Features of the Model}

In this section we discuss the features of the data driving our estimates of the parameters determining the implications of the firm-specific and homogeneous capital models for the frequency at which firms re-optimize prices.

Our point estimate of $\gamma(0.040)$ implies that a temporary one percent change in marginal cost results in only a 0.031 percent change in the aggregate price level. ${ }^{27}$ The small value of $\gamma$ lies at the heart of the tension between the micro and macro implications of the homogeneous capital model.

We now argue that any reasonable estimate of $\gamma$ must be low. In Figure 4a we plot $\Delta \hat{\pi}_{t}-\beta \Delta \hat{\pi}_{t+1}$ against our measure of the log of marginal cost, $\hat{s}_{t}{ }^{28}$ The distribution of $\Delta \hat{\pi}_{t}-\beta \Delta \hat{\pi}_{t+1}$ is at best weakly related to the magnitude of $\hat{s}_{t}{ }^{29}$ The relatively flat curve in Figure 4a has a slope equal to our point estimate of $\gamma(0.040)$. Significantly, this curve passes through the central tendency of the data. The steeper curve in Figure 4a is drawn for a value of $\gamma$ equal to 0.9 , a value which implies that in the homogeneous capital model firms

\footnotetext{
${ }^{27}$ This estimate is consistent with results in the literature. See Eichenbaum and Fisher (2004) and the references therein.

${ }^{28}$ We set $\beta=1.03^{-.25}$. Also, we measure marginal productivity by labor's share in GDP. In our model this is the correct measure if fixed costs are zero. This measure is approximately correct here, since our estimate of $\phi$ is close to zero.

${ }^{29}$ Eichenbaum and Fisher (2004) argue that their estimates of $\gamma$ are robust to alternative measures of marginal cost.
} 
change prices roughly once every 1.5 quarters. Figure 4 a show that raising $\gamma$ to 0.9 leads to a drastic deterioration in fit.

Equation (2.32) implies that the magnitude of the residuals from the lines in Figure 4a cannot be used a formal measure of model fit. We should focus on the size of residuals when the data are replaced by their projection onto date $t$ information, because then (2.32) implies that least squares consistently recovers the true value of $\gamma$. Figure $4 \mathrm{~b}$ is the analog to Figure $4 \mathrm{a}$, with variables replaced by their projection onto $\digamma_{t} \equiv\left\{\Delta \pi_{t-s}-\beta \Delta \pi_{t+1-s}, \hat{s}_{t-s} ; s=1,2\right\}$. We note that Figures $4 \mathrm{a}$ and $4 \mathrm{~b}$ are very similar. Our conclusions are unchanged: the data on inflation and marginal cost suggest that $\gamma$ is small..$^{30}$

The low estimated value of $\gamma$ provides a different perspective on the inflation inertia puzzle, particularly the weak response of inflation to monetary policy shocks. Solving (2.32) forward we obtain

$$
\Delta \hat{\pi}_{t}=\gamma \sum_{j=0}^{\infty} \beta^{j} E_{t} \hat{s}_{t+j} .
$$

This relation makes clear why many authors incorporate features like variable capital utilization and sticky wages into their models. These features can reduce the response of expected marginal cost to shocks. ${ }^{31}$ Relation (6.1) reveals another way to account for inflation inertia: assign a small value to $\gamma$. The evidence in Figure $4 \mathrm{a}$ and $4 \mathrm{~b}$ indicates that a small value of $\gamma$ must be part of any successful resolution of the inflation inertia puzzle.

A low value of $\gamma$ is clearly a problem for the homogeneous capital model. This is because the model then implies that firms re-optimize prices very infrequently, e.g., at intervals of roughly six quarters. ${ }^{32}$ So to get the macro data right (i.e., a low $\gamma$ ) we must make assumptions about the frequency at which firms re-optimize prices that seem implausible in light of the micro data. In contrast, suppose we adopt the more plausible assumption that firms re-optimize prices on average once every 1.5 quarters. Then the homogeneous capital model implies $\gamma=0.9$. But this means that the model gets the macro data wrong.

To explain how the firm-specific capital model is able to resolve the micro-macro pricing conflict, we recall the intuition discussed in the introduction. In the firm-specific capital model, marginal cost is increasing in output. In the homogeneous capital model marginal cost is constant. Figure 5 displays the initial marginal cost curves of the homogeneous and firm-specific capital models, denoted by $M C_{0, h}$ and $M C_{0, f}$. Both of these curves intersect the marginal revenue curve at point $A$. So, both firms produce the same amount, $Q_{0}$, and set the same price, $P_{0}$. We now suppose that an exogenous shock pushes both marginal cost

\footnotetext{
${ }^{30}$ We obtain the same results whether we work with $\Delta \hat{\pi}_{t}$ or with $\hat{\pi}_{t}$.

${ }^{31}$ See, for example, Ball and Romer (1990), Christiano et al. (2005), Dotsey and King (2001) and Smets and Wouters (2003).

${ }^{32}$ This is a straightforward implication of the homogeneous capital model discussed above, according to which $\gamma=\left(1-\xi_{p}\right)\left(1-\beta \xi_{p}\right) / \xi_{p}$.
} 
curves up in a parallel way, by the same amount, to $M C_{1, h}$ and $M C_{1, f}$. In the homogeneous capital model, the marginal revenue and new marginal cost curves intersect at the point, $B$. The firm chooses the new price $P_{1}$. In the firm-specific capital model, the intersection of marginal cost and revenue occurs at $B^{\prime}$ and a firm chooses a price, $P_{2}$. We note that $P_{1}>P_{2}$. The steeper is the slope of the marginal cost curve, the lower is $P_{2}$. Since the aggregate price level is just the average of individual firm prices, this intuition explains why increasing the slope of the marginal cost curve reduces the value of $\gamma$.

The key parameter which governs the slope of the marginal cost curve is $\sigma_{a}$. The larger is this parameter, the steeper is the marginal cost curve. The logic in the previous paragraph suggests that for a fixed value of $\xi_{p}$, the larger is $\sigma_{a}$, the lower is $\gamma$. But other things equal, a lower $\xi_{p}$ implies a higher $\gamma$. These observation suggest that for a given value of $\gamma, \xi_{p}$ is a decreasing function of $\sigma_{a}$. In fact, our point estimate of $\sigma_{a}$ is large which helps explain why the value of $\xi_{p}$ implied by the firm-specific model is low.

What is it about the data that leads to a large point estimate for $\sigma_{a}$ ? We recompute the impulse responses implied by our model, holding all but one of the model parameters at their estimated values. The exception is $\sigma_{a}$ which we set to 0.01 . The new value of $\sigma_{a}$ has two effects on the model impulse response functions. First, the responses of capital utilization to both technology shocks are stronger. The responses are so strong that, at several horizons, they lie outside the corresponding empirical confidence intervals. Second, investment falls after a neutral technology shock. The reason for this decline is that when $\sigma_{a}$ is small, the rise in capital utilization that occurs after a positive neutral technology shock leads to a fall in the rate of return on investment which generates a fall in investment. ${ }^{33}$ This fall in investment is inconsistent with our VAR-based estimate that investment rises after a neutral shock (see Figure 2). The two effects of a smaller value of $\sigma_{a}$ explain why our estimation criterion settles on a high value of $\sigma_{a}$.

In Table 2 and 3 we report the results of estimating the model subject to the constraint that $\sigma_{a}$ is a small number, 0.01. Table 4 shows that consistent with our intuition, the homogeneous and firm-specific capital model now yield similar implications for the frequency with which firms re-optimize prices.

To verify our intuition about why our benchmark estimate of $\sigma_{a}$ is high, we re-estimate the model including only the responses to a monetary policy shock in the criterion. We report our results in Tables 2 and 4. Our point estimate of $\sigma_{a}$ falls from 2.01 to 0.007.

\footnotetext{
${ }^{33}$ To understand this observation, consider a simplified version of our economy in which the resource constraint is:

$$
C_{t}+\bar{K}_{t+1} \equiv\left(u_{t} \bar{K}_{t}\right)^{\alpha} z_{t}^{1-\alpha}+\left(1-\delta-a\left(u_{t}\right)\right) \bar{K}_{t} .
$$

In this economy, the rate of return on investment is $M P_{K, t}+\left(1-\delta-a\left(u_{t}\right)\right)$. It is easy to verify that this expression is decreasing in $u_{t}$, once we take into account the efficiency condition associated with the optimal choice of $u_{t}$.
} 
This is consistent with the estimates in Christiano et al. (2005). The lower value of $\sigma_{a}$ allows the model to better capture the estimated rise in capital utilization that occurs after a monetary policy shock, without paying a penalty for the counterfactual implication that investment falls after a neutral technology shock. ${ }^{34}$ We note that with a higher value of $\sigma_{a}$, the homogeneous and firm- specific models both imply that firms re-optimize prices on average roughly once every 3.5 quarters.

To pursue our intuition about the benchmark estimate of $\sigma_{a}$ we also re-estimate the model including only a capital embodied technology shock in the estimation criterion. Tables 2,3 and 4 show that our results are similar to the benchmark results except that our estimate of $\sigma_{a}$ is higher. The higher value of $\sigma_{a}$ dampens the response of capital utilization to a capital embodied technology shock, bringing the model response closer to the VAR-based response. With a higher value of $\sigma_{a}$, the implications of the homogeneous and firm-specific capital models are even more different than those corresponding to our benchmark estimates.

We also re-estimate the model including only a neutral technology shock in the estimation criterion. Table 2 shows that our estimate of $\sigma_{a}$ is extremely high. This high value of $\sigma_{a}$ allows the model to account for the rise in investment that occurs after a neutral technology shock. Tables 2 and 4 also indicate that the estimation criterion chooses values for the structural parameters which imply that firms re-optimize prizes on average once every quarter. This allows the model to account for the drop in inflation that occurs after a positive neutral technology shock (see Figure 2).

Figure 5 suggests that a high elasticity of demand also works to reduce a firm's incentive to raise price after an exogenous increase in marginal cost, i.e. a low value of $\lambda_{f}$ reduces $\gamma$. While our estimation criterion is very insensitive to $\lambda_{f}$, it weakly prefers a very low value for this variable. To examine the role played by $\lambda_{f}$, we re-estimate the model imposing $\lambda_{f}=1.04$ and 1.20. The first of these values of $\lambda_{f}$ corresponds to Bowman's (2003) estimate for the economy as a whole. The second value of $\lambda_{f}$ is equal to the point estimate in Christiano, et al (2005). Table 2 shows that imposing different values of $\lambda_{f}$ has very little impact on the estimated values of the key structural parameters of the model. Table 4 shows that the main effect of a higher value of $\lambda_{f}$ is to reduce the frequency with which firms re-optimize prices in the firm-specific capital model. For example, when $\lambda_{f}=1.20$, firms model re-optimize prices on average once every 3.5 quarters. We conclude that to resolve the micro - macro pricing puzzle in our framework we are compelled to take the view that $\lambda_{f}$ is close to one. This last result may reflect our assumption that intermediate goods firms face a constant elasticity of demand. Other specifications of demand, like the one proposed in Kimball (1995), break the link between the steady state markup and the elasticity of demand away from steady state.

\footnotetext{
${ }^{34}$ This reconciles our results with those reported in Christiano et al. (2005) who report a low estimated value of $\sigma_{a}$ based on an estimation criterion that includes only the responses to a monetary policy shock.
} 
Incorporating changes like these may make it possible to rationalize a low $\gamma$ with a low value of $\xi_{p}$ and a higher value of $\lambda_{f}$.

Finally, we assess the robustness of our results to the lag length in the VAR underlying our structural estimates, setting $q=6$, rather than 4 . Table 2 and 3 show that, taking sampling uncertainty into account, our basic results are unaffected. Table 4 indicates that in the homogeneous and firm-specific capital models, firms re-optimize prices on average once every 1.12 and 3.13 quarters respectively.

\section{Choosing Between the Homogeneous and Firm-Specific Capital Models}

The homogeneous and firm-specific capital models imply that firms re-optimize prices on average once every 1.5 and 5.6 quarters, respectively. In the introduction we argue that these results point in favor of firm-specific capital model. We now document an even more powerful reason for preferring that model: the estimated homogeneous capital model predicts, implausibly, that a small subset of firms produce the bulk of total output after a monetary policy shock. The firm-specific capital model does not suffer from this shortcoming.

To document these findings, we consider the cross-firm distribution of prices and output after a monetary policy shock. We suppose that the economy is in a steady state up until period 0 . In the steady state, each firm's price and quantity is the same. An expansionary monetary policy shock occurs in period 1. Given the timing convention in our model, prices and output levels are the same across firms at the end of period 1 . In period 2, a fraction, $1-\xi_{p}$, of firms re-optimize their price. The other firms firms update their price according to $(2.9)$. In period 3 there are four types of firms: (i) a fraction, $\left(1-\xi_{p}\right)^{2}$, of firms that re-optimize in periods 2 and 3 ; (ii) a fraction, $\xi_{p}^{2}$, of firms that do not re-optimize in periods 2 or 3 ; (iii) a fraction, $\left(1-\xi_{p}\right) \xi_{p}$, which re-optimize in period 2 and not in period 3; and (iv) a fraction, $\xi_{p}\left(1-\xi_{p}\right)$, of firms that do not re-optimize in period 2 , but do re-optimize in period 3 . In period $s$ there are $2^{s-1}$ different types of firms.

We calculate the distribution of output and relative prices across firms in period $s=4$. Figures $6 \mathrm{a}$ and $6 \mathrm{~b}$ summarize our findings for the homogeneous capital version of the model. Consider the integers $1,2,3$, and 4 on the horizontal axes of these figures. The first of these integers pertains to firms that did not re-optimize their price in periods 2,3 and 4 . The integers $j=2,3$ and 4 , pertain to firms who last re-optimized in period $j$. Figure 6 a shows the share of output (black bars) and the fraction of firms (grey bars) produced by the different types of firms. (In the homogeneous capital model, the price and output levels of all firms within each of these four groups are the same.) Figure 6b shows the log deviation of price of the firms in each group from the aggregate price. 
We note several features of Figure $6 \mathrm{a}$ and $6 \mathrm{~b}$. First, a small fraction of the firms are producing a disproportionate share of the output. Indeed, our linearized solution implies a small subset of firms produce more than 100 percent of output. Firms who re-optimize set their price so high that their output is negative. This is clearly a nonsensical solution indicating that the log linear solution algorithm breaks down. Firms who are predicted to produce negative output would actually produce zero output, close down or change their nominal price.

A key factor driving the implication that a small subset of firms produce more than one hundred percent of output is the high elasticity of demand for a firm's output ( $\lambda_{f}$ is small) in the estimated benchmark model. It would be possible to overturn this implication by imposing a higher value of $\lambda_{f}$. But in our view this is not a satisfactory way to rescue the homogeneous capital model: when we impose $\lambda_{f}=1.20$ and re-estimate the model, we find that firms re-optimize prices an intervals of time that are implausibly high. (see Tables 2 and 4)

We now turn to the firm-specific capital model. Figures $6 \mathrm{c}$ and $6 \mathrm{c}$ are the analogs to Figures $6 \mathrm{a}$ and $6 \mathrm{~b}$. Figure $6 \mathrm{c}$ shows that the dramatic degree of inequality of production associated with the homogeneous capital model no longer obtains and firms are not predicted to produce negative amounts of output. Still, there is some inequality in the level of production at individual firms. The average level of production by firms in a particular category corresponds to the ratio of the black bar (total production in that group) to the grey bar (number of firms in that group). In period 4, these averages are 3.3, 2.1, 1.3, and 0.6 for firms that last optimized in periods 1, 2, 3 and 4, respectively. So, the typical firm that has not been able to re-optimize its price since the monetary policy shock produces over 5 times as much as a firm that has not been able to re-optimize since the shock occurred. In later periods, the extent of the inequality in production is substantially mitigated..$^{35}$

We conclude that the microeconomic implications of the estimated homogeneous capital model are much less plausible than those of the firm-specific capital model. Since the two models have the same implications for macro data, we prefer the firm-specific capital model. To formally assess the micro implications of the firm-specific capital discussed above we would have to have data on the response of the actual cross-firm distribution of output and prices to a monetary policy shock. Unfortunately, these data are not available.

\footnotetext{
${ }^{35}$ One measure of the degree of inequality in production is provided by the Gini coefficient. In periods 4 , 8 and 16 , these are $0.24,0.40$ and 0.68 for firm-specific capital version of the model.
} 


\section{Conclusion}

We construct a dynamic general equilibrium model of cyclical fluctuations that accounts for inflation inertia even though firms re-optimize prices on average once every 1.5 quarters. To obtain this result we assume that capital is firm-specific. If we assume that capital is homogenous we can account for inflation inertia. However, this version of the model has micro implications that are implausible: firms re-optimize their prices on average once every 5.6 quarters and a monetary policy shock induces extreme dispersion in prices and output across firms. These considerations lead us to strongly prefer the firm-specific capital model.

We conclude by noting an important shortcoming of our model. Under our identifying assumptions, inflation responds very slowly to a monetary policy shock but quickly drops after a positive neutral technology shock. So inflation is inertial with respect to monetary policy shocks, but not with respect to technology shocks. Our structural economic model can account for the first observation but not the second observation. We suspect that modifying the model so that firms have direct information about persistent technology shocks but have difficulty distinguishing monetary policy shocks from transitory idiosyncratic demand shocks would be a useful way of remedying this shortcoming of our model. ${ }^{36}$ We leave this task to future research.

\footnotetext{
${ }^{36}$ Mackowiak and Wiederholt (2004) obtain a closely related result in a rational inattention model where price setting firms optimally decide what to observe, subject to a constraint on information flow.
} 


\section{References}

[1] Altig, David, Lawrence J. Christiano, Martin Eichenbaum, and Jesper Linde. 2003. "The Role of Monetary Policy in the Propagation of Technology Shocks." Manuscript, Northwestern University.

[2] Altig, David, Lawrence J. Christiano, Martin Eichenbaum, and Jesper Linde. 2004. Technical Appendix to "Firm-Specific Capital, Nominal Rigidities and the Business Cycle." Manuscript, Northwestern University.

[3] Alves, Nuno. 2004. "Nominal Wage Inertia in General Equilibrium Models." 2004. Bank of Portugal, Working Paper 15 - 04.

[4] Ball, Laurence and David Romer. 1990. "Real Rigidities and the Non-neutrality of Money." Review of Economic Studies. 57 (April): 183-203.

[5] Basu, Susanto, and John Fernald. 1994. "Constant returns and small markups in U.S. manufacturing." Working paper, International Finance Discussion Paper No. 483, Board of Governors of the Federal Reserve System.

[6] Bierens, Herman J.. 2004. "Information Criteria and Model Selection." Manuscript, Penn State University.

[7] Bils, Mark, and Pete Klenow. 2004. "Some Evidence on the Importance of Sticky Prices." Journal of Political Economy. 112 (October): 947-985.

[8] Boldrin, Michele, Christiano, Lawrence J., and Jonas Fisher. 2001. "Habit Persistence, Asset Returns and the Business Cycle." American Economic Review. 91 (March): 149166.

[9] Bowman, David. 2003. "Market and Inflation." International Finance Discussion Papers, Number 783, October.

[10] Calvo, Guillermo. 1983, "Staggered Prices in a Utility-Maximizing Framework." Journal of Monetary Economics. 12 (September): 383-98.

[11] Chari, V.V., Patrick Kehoe, and Ellen McGrattan. 2004. "Are Structural VARs Useful Guides for Developing Business Cycle Theories?"Manuscript, Federal Reserve Bank of Minneapolis.

[12] Christiano, Lawrence J. 2002. "Solving Dynamic Equilibrium Models by a Method of Undetermined Coefficients." Computational Economics. 20 (October): 21 - 55.. 
[13] Christiano, Lawrence J. 2004. "Firm-Specific Capital and Aggregate Inflation Dynamics in Woodford's Model." manuscript, http://www.faculty.econ.northwestern.edu/faculty/christiano/research/firmspecific/svensson.pdf.

[14] Christiano, Lawrence J., and Martin Eichenbaum. 1992. "Current Real-Business-Cycle Theories and Aggregate Labor-Market Fluctuations," American Economic Review. 82 (June): 430-50.

[15] Christiano, Lawrence J., Martin Eichenbaum, and Charles Evans. 1999. "Monetary Policy Shocks: What Have We Learned and to What End?". In Handbook of Macroeconomics, vol. 1A, edited by Michael Woodford and John Taylor, Amsterdam; New York and Oxford: Elsevier Science, North-Holland.

[16] Christiano, Lawrence, Eichenbaum, Martin, and Charles Evans. 2005. "Nominal Rigidities and the Dynamic Effects of a Shock to Monetary Policy.". Forthcoming, Journal of Political Economy.

[17] Christiano, Lawrence J., Martin Eichenbaum, and Robert Vigfusson. 2003a. "What Happens After a Technology Shock?" Manuscript, Northwestern University.

[18] Christiano, Lawrence J., Eichenbaum, Martin, and Robert Vigfusson. 2003b. "The Response of Hours to a Technology Shock: Evidence Based on Direct Measures of Technology." Journal of the European Economic Association. 2 (May): 381-395.

[19] Christiano, Lawrence J., Roberto Motto, and Massimo Rostagno. 2003. "The Great Depression and the Friedman-Schwartz Hypothesis." Journal of Money, Credit and Banking. 35, no. 6, pt. 2 (December): 1119-1198.

[20] Coenen, Gunter, and Andrew Levin. 2004. "Identifying the Influences of Real and Nominal Rigidities in Aggregate Price-Setting Behavior." Manuscript, Board of Governors of the Federal Reserve System.

[21] Cooley, Thomas, and Dwyer. 1998. "Business Cycle Analysis Without Much Theory: A Look at Structural VARs." Journal of Econometrics. 83 (March): 57-88.

[22] de Walque, Gregory, Frank Smets, and Raf Wouters. 2004. "Price Setting in General Equilibrium: Alternative Specifications." Manuscript, European Central Bank.

[23] DiCecio, Riccardo. 2004. "Comovement: it's not a puzzle." Manuscript, Federal Reserve Bank of St. Louis. 
[24] Dotsey, Michael, and Robert King. 2001. "Pricing, Production and Persistence." National Bureau of Economic Research working paper 8407.

[25] Edge, Rochelle M.. 2004. "The Responses of Wages and Prices to Technology Shocks." Manuscript, Board of Governors of the Federal Reserve System.

[26] Edge, Rochelle M., Thomas Laubach, and John C. Williams. 2004. "Learning and Shifts in Long-run Productivity Growth." Manuscript, Federal Reserve Board of Governors.

[27] Eichenbaum, Martin, and Jonas Fisher. 2004. "Evaluating the Calvo Model of Sticky Prices."' National Bureau of Economic Research working paper number 10617.

[28] Erceg, Christopher J., Henderson, Dale, W., and Andrew T. Levin. 2000. "Optimal Monetary Policy with Staggered Wage and Price Contracts." Journal of Monetary Economics, 46 (October): 281-313.

[29] Erceg, Christopher J., Luca Guerrieri, and Christopher Gust. 2003. "Can Long-Run Restrictions Identify Technology Shocks?". Manuscript, Board of Governors of the Federal Reserve System.

[30] Fisher, Jonas. 2003. "Technology Shocks Matter." Chicago Federal Reserve Bank working paper, 2001-14.

[31] Francis, Neville, and Valerie A. Ramey. 2002. "Is the Technology-Driven Real Business Cycle Hypothesis Dead? Shocks and Aggregate Fluctuations Revisited." NBER Working Paper number 8726.

[32] Gali, Jordi, and Mark Gertler. 1999. "Inflation Dynamics: A Structural Econometric Analysis." Journal of Monetary Economics, 44 (October): 195-222.

[33] Gali, Jordi. 1999. "Technology, Employment, and the Business Cycle: Do Technology Shocks Explain Aggregate Fluctuations?" American Economic Review. 89 (March): 249271.

[34] Gali, Jordi, J. David Lopez-Salido, and Javier Valles. 2003. "Technology Shocks and Monetary Policy: Assessing the Fed's Performance." Journal of Monetary Economics. 50 (May): $723-743$.

[35] Golosov, Mikhail, and Robert E. Lucas, Jr.. 2003. "Menu Costs and Phillips Curves." NBER Working Paper number 10187.

[36] Hamilton, James D. 1994. Time Series Analysis, Princeton University Press, Princeton, New Jersey. 
[37] Hall, Robert, 1988. "The Relation Between Price and Marginal Cost in U.S. Industry." Journal of Political Economy. 96 (October): 921-47.

[38] Kimball, Miles. 1995. "The Quantitative Analytics of the Basic Neomonetarist Model." Journal of Money, Credit and Banking 27(4), part II: 1241-1277.

[39] Klenow, Peter, and Oleg Kryvtsov. 2004. "State-Dependent or Time-Dependent Pricing: Does it Matter for Recent U.S. Inflation."Manuscript, Stanford University.

[40] Lucas, Robert E., Jr.. 1988. "Money Demand in the United States: A Quantitative Review," Carnegie-Rochester Conference Series on Public Policy 29 (Autumn): 137 167.

[41] Mackowiak, Bartosz, and Mirko Wiederholt. 2004. "Optimal Sticky Prices Under Rational Inattention." Manucsript, Humboldt University, Berlin.

[42] Prescott, Edward. 1986. "Theory Ahead of Business Cycle Measurement." Federal Reserve Bank of Minneapolis Quarterly Review, 10 (Fall): 9-22.

[43] Sveen, Tommy, and Lutz Weinke. 2004a. "Pitfalls in the Modeling of Forward-Looking Price Setting and Investment Decisions." Manuscript, Universitat Pompeu Fabra.

[44] Sveen, Tommy, and Lutz Weinke. 2004b. "New Perspectives on Capital and Sticky Prices." Norges Bank Working Paper 2004/3.

[45] Rotemberg, Julio J., and Michael M. Woodford. 1995. "Dynamic General Equilibrium Models with Imperfectly Competitive Product Markets." In Frontiers of Business Cycle Research, edited by Thomas F. Cooley. Princeton, NJ: Princeton University Press.

[46] Rotemberg, Julio J., and Michael M. Woodford. 1997. "An Optimization-Based Econometric Framework for the Evaluation of Monetary Policy." National Bureau of Economic Research Macroeconomics Annual 1997, edited by Ben S. Bernanke and Julio J. Rotemberg. Cambridge, MA: MIT Press.

[47] Sbordone, Argia. 2002. "Prices and Unit Labor Costs: A New Test of Price Stickiness." Journal of Monetary Economics 49 (2): 265-292.

[48] Shapiro, Matthew, and Mark Watson. 1988. "Sources of Business Cycle Fluctuations." NBER, Macroeconomics Annual 1988, edited by Stanley Fischer. Cambridge, MA: MIT Press.

[49] Sims, Christopher. 1994. "A Simple Model for the Determination of the Price Level and the Interaction of Monetary and Fiscal Policy." Economic Theory, 4: 381-399. 
[50] Smets, Frank, and Raf Wouters. 2003. "An Estimated Dynamic Stochastic General Equilibrium Model of the Euro Area," Journal of the European Economic Association 1 (September): 1123-1175.

[51] Smets, Frank, and Raf Wouters. 2004. "Price Setting in General Equilibrium: Alternative Specifications." Manuscript, European Central Bank.

[52] Schmitt-Grohe, Stefanie, and Martin Uribe. 2004. "Optimal Fiscal and Monetary Policy Under Sticky Prices." Journal of Economic Theory 114 (February): 198-230.

[53] Sveen, Tommy, and Lutz Weinke. 2004. "Pitfalls in the Modeling of Forward-Looking Price Setting and Investment Decisions." Manuscript, Universitat Pompeu Fabra.

[54] Woodford, Michael M.. 1996. "Control of the Public Debt: A Requirement for Price Stability." NBER Working Paper number 5684.

[55] Woodford, Michael M.. 2003. Interest and Prices, Foundations of a Theory of Monetary Policy, Princeton University Press.

[56] Woodford, Michael M.. 2004. "Inflation and Output Dynamics with Firm-Specific Investment." Manuscript, Princeton University. 


\section{Appendix A: Accuracy of Impulse Response Functions}

Estimates of the dynamic response of aggregate variables to policy and technology shocks play a key role in our analysis. In this appendix we present evidence on the sampling properties of our VAR-based estimator of impulse response functions. We begin by generating a large number of artificial data sets, each having the same length as our U.S. sample. We then feed the artificial data to the same VAR estimation program that we apply to the U.S. data. The analysis allows us to study the bias and variance properties of our impulse response function estimator.

The first step in constructing the artificial data sets is to generate data on the model counterpart of (3.1) using our estimated equilibrium model. Denote these data by $\left\{Y_{t}^{\text {Model }}\right\}$. The perspective taken in our analysis is that the actual data, $Y_{t}$, are an orthogonal sum of data driven by the identified shocks plus data driven by the other shocks in the economy (see (3.11)). Consistent with this perspective, the data we feed to our VAR is $\tilde{Y}_{t}$, where

$$
\tilde{Y}_{t}=Y_{t}^{\text {Model }}+Y_{t}^{\text {Other }} .
$$

To generate artificial data on $Y_{t}^{\text {Other }}$ we use (3.10), where $B(L)$ and $C_{2}$ are set to their estimated values. The innovations driving $Y_{t}^{\text {Model }}$ were drawn from the Normal distribution, while the innovations driving $Y_{t}^{\text {Other }}$ were sampled from their fitted counterparts.

The results are reported in Figures 7. Solid lines are the true impulse response functions, by which we mean the response in the equilibrium model used to generate $Y_{t}^{\text {Model }}$. The dotted line is the median, in repeated samples of 160 artificial observations each, of the impulse response functions obtained by estimating a 4-lag, 10 variable VAR. The grey area is the 95 confidence interval. ${ }^{37}$

We note that there is very little small sample bias in our estimator. Two exceptions occur in the response of output and consumption to a neutral technology shock. This discrepancy is reduced when we extend the number of lags in the VAR to six. This reduction in the discrepancy is why re-estimate the parameters of our structural model using the impulse response functions and associated variance covariance matrix from a six lag VAR. As discussed in the text our basic results are unaffected by working with the six lag VAR (see Tables 2, 3 and 4$)$.

\footnotetext{
${ }^{37}$ The confidence interval for a given lag impulse response was computed as follows. Responses across 1,000 artificial data sets were ordered from smallest to largest. The 95 percent confidence interval is defined by the $25^{\text {th }}$ and the $975^{\text {th }}$ elements in this ordering.
} 


\begin{tabular}{|c|c|c|c|c|c|c|c|}
\hline \multicolumn{8}{|c|}{ TABLE 2: ESTIMATED PARAMETER VALUES $\zeta_{1}$} \\
\hline Model & $\lambda_{f}$ & $\xi_{w}$ & $\gamma$ & $\sigma_{a}$ & $b$ & $S^{\prime \prime}$ & $\epsilon$ \\
\hline Benchmark & 1.01 & $\begin{array}{l}0.72 \\
(0.13) \\
\end{array}$ & $\begin{array}{l}0.040 \\
(0.020)\end{array}$ & $\begin{array}{l}2.02 \\
(2.32) \\
\end{array}$ & $\begin{array}{l}0.70 \\
(0.04)\end{array}$ & $\begin{array}{l}3.28 \\
(1.69) \\
\end{array}$ & $\begin{array}{l}0.80 \\
(0.21)\end{array}$ \\
\hline Monetary Shocks Only & $\begin{array}{l}1.08 \\
(0.10)\end{array}$ & $\begin{array}{l}0.62 \\
(0.07)\end{array}$ & $\begin{array}{l}0.106 \\
(0.061)\end{array}$ & $\begin{array}{l}0.01 \\
(0.01)\end{array}$ & $\begin{array}{l}0.73 \\
(0.05)\end{array}$ & $\begin{array}{l}3.63 \\
(1.73)\end{array}$ & $\begin{array}{l}0.82 \\
(0.19)\end{array}$ \\
\hline Neutral Technology Shocks Only & $\begin{array}{l}2.05 \\
\text { (n.a.) }\end{array}$ & $\begin{array}{l}0.93 \\
\text { (n.a.) }\end{array}$ & $\begin{array}{c}9.5 e+006 \\
(\text { n.a. })\end{array}$ & $\begin{array}{c}2.3 e+046 \\
(\text { n.a. })\end{array}$ & $\begin{array}{c}0.054 \\
(\text { n.a. })\end{array}$ & $\begin{array}{l}1.00 \\
\text { (n.a.) }\end{array}$ & $\begin{array}{l}0.97 \\
(\text { n.a. })\end{array}$ \\
\hline Embodied Technology Shocks Only & 1.01 & $\begin{array}{l}0.70 \\
(0.36)\end{array}$ & $\begin{array}{l}0.033 \\
(0.020)\end{array}$ & $\begin{array}{l}5.84 \\
(8.03)\end{array}$ & $\begin{array}{l}0.23 \\
(0.29)\end{array}$ & $\begin{array}{l}0.90 \\
(0.73)\end{array}$ & $\begin{array}{l}1.24 \\
(0.71)\end{array}$ \\
\hline $\begin{array}{l}\text { Low Cost of Varying } \\
\text { Capital Utilization }\end{array}$ & $\begin{array}{l}1.46 \\
(1.93)\end{array}$ & $\begin{array}{r}0.69 \\
(0.12) \\
\end{array}$ & $\begin{array}{l}0.050 \\
(0.031)\end{array}$ & .01 & $\begin{array}{l}0.69 \\
(0.05)\end{array}$ & $\begin{array}{l}2.79 \\
(1.47)\end{array}$ & $\begin{array}{l}0.79 \\
(0.21)\end{array}$ \\
\hline Intermediate Markup & 1.04 & $\begin{array}{l}0.72 \\
(0.13) \\
\end{array}$ & $\begin{array}{l}0.042 \\
(0.022)\end{array}$ & $\begin{array}{l}1.91 \\
(2.23)\end{array}$ & $\begin{array}{l}0.70 \\
(0.04)\end{array}$ & $\begin{array}{l}3.18 \\
(1.65)\end{array}$ & $\begin{array}{l}0.80 \\
(0.21)\end{array}$ \\
\hline High Markup & 1.20 & $\begin{array}{l}0.69 \\
(0.12)\end{array}$ & $\begin{array}{l}0.050 \\
(0.031)\end{array}$ & $\begin{array}{l}1.46 \\
(1.93)\end{array}$ & $\begin{array}{l}0.69 \\
(0.05)\end{array}$ & $\begin{array}{l}2.79 \\
(1.47)\end{array}$ & $\begin{array}{l}0.79 \\
(0.21)\end{array}$ \\
\hline Benchmark (6 lag VAR) & 1.01 & $\begin{array}{l}0.93 \\
(0.07)\end{array}$ & $\begin{array}{l}0.152 \\
(0.229)\end{array}$ & $\begin{array}{l}10.54 \\
(28.11)\end{array}$ & $\begin{array}{l}0.72 \\
(0.06)\end{array}$ & $\begin{array}{c}2413.49 \\
(7368.62)\end{array}$ & $\begin{array}{l}0.81 \\
(0.20)\end{array}$ \\
\hline
\end{tabular}


Figure 1: Response to a monetary policy shock (o - Model, - VAR, grey area - $95 \%$ Confidence Interval)
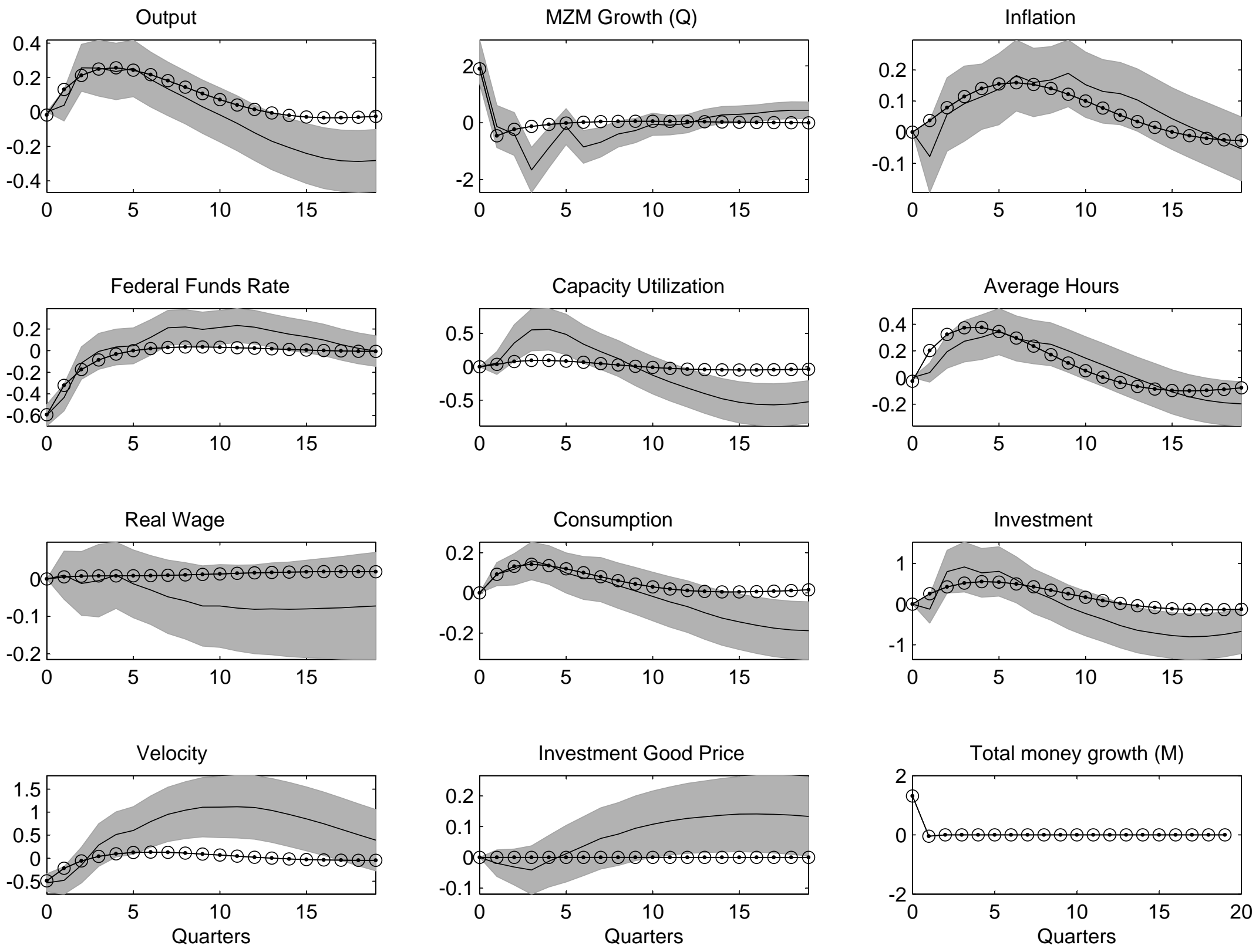
Figure 2: Response to a neutral technology shock (o - Model, - VAR, grey area - 95 \% Confidence Interval)
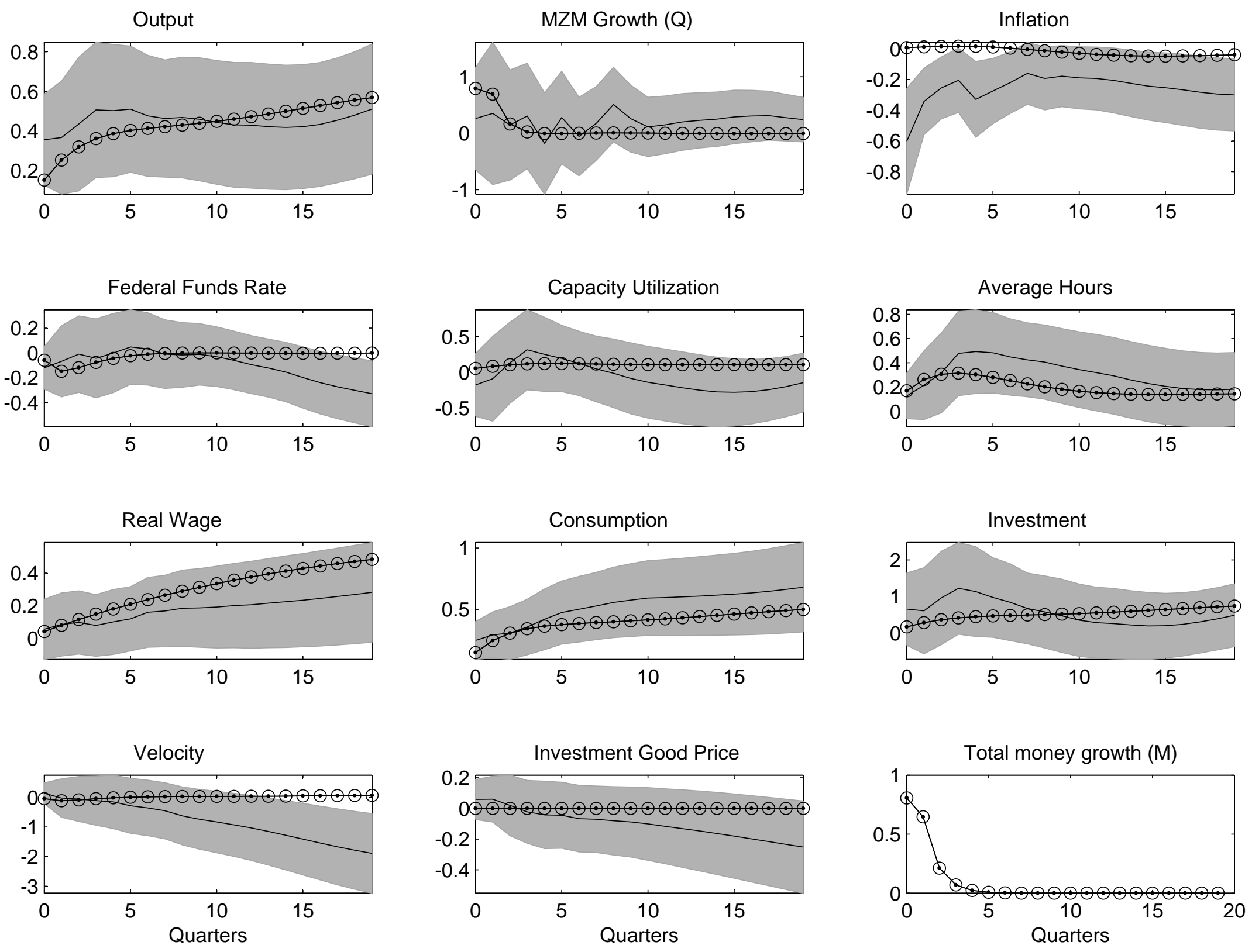
Figure 3: Response to an embodied technology shock (o - Model, - VAR, grey area - $95 \%$ Confidence Interval)
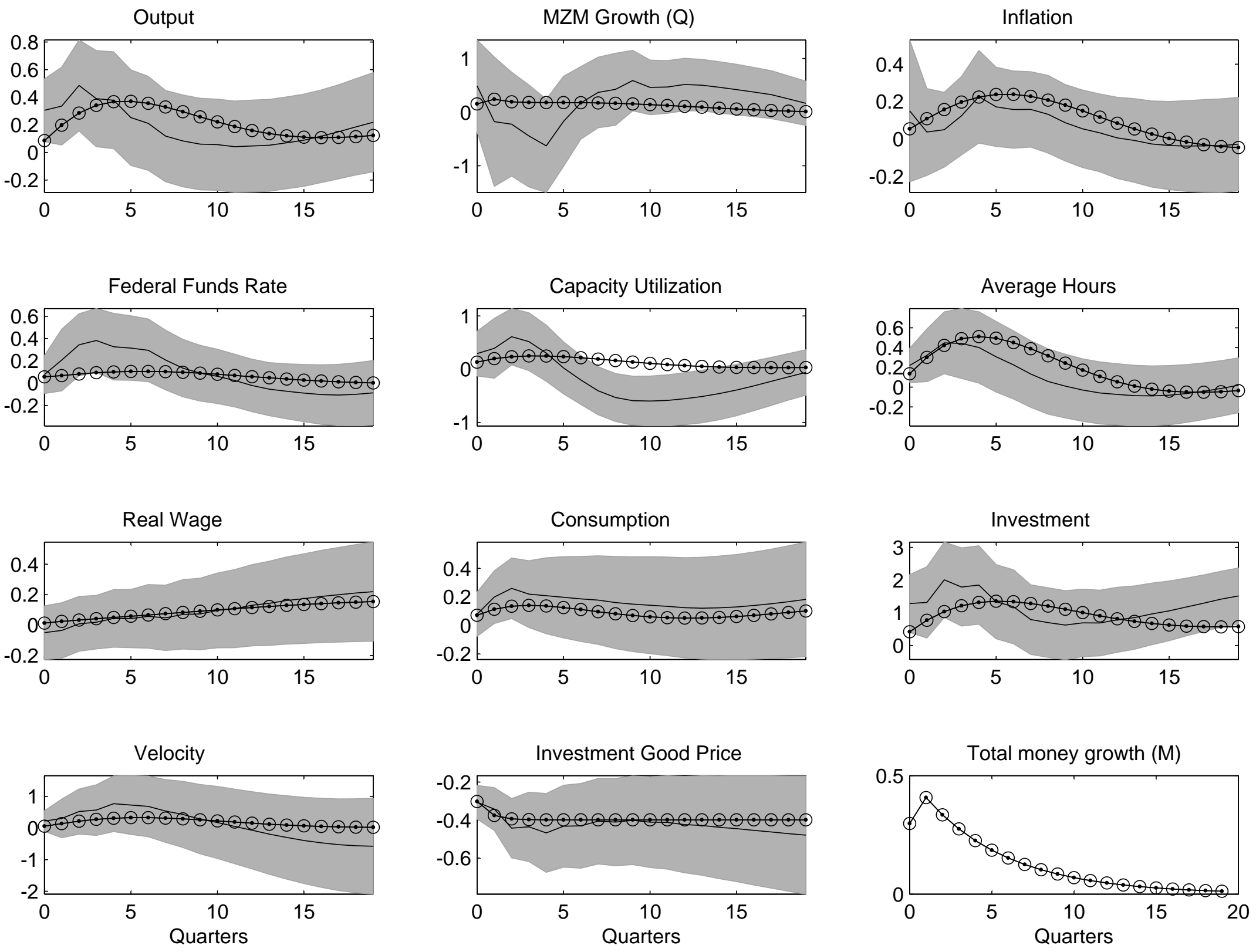


\begin{tabular}{|c|c|c|c|c|c|c|c|c|c|c|c|}
\hline \multicolumn{12}{|c|}{ TABLE 3: ESTIMATED PARAMETER VALUES $\zeta_{2}$} \\
\hline$\rho_{x M}$ & $\sigma_{M}$ & $\rho_{\mu_{z}}$ & $\sigma_{\mu_{z}}$ & $\rho_{x z}$ & $c_{z}$ & $c_{z}^{p}$ & $\rho_{\mu_{\Upsilon}}$ & $\sigma_{\mu \Upsilon}$ & $\rho_{x \Upsilon}$ & $c_{\Upsilon}$ & $c_{\Upsilon}^{p}$ \\
\hline \multicolumn{12}{|c|}{ Benchmark Model } \\
\hline $\begin{array}{c}-0.03 \\
(0.11)\end{array}$ & $\begin{array}{l}0.33 \\
(0.08)\end{array}$ & $\begin{array}{l}0.90 \\
(0.11)\end{array}$ & $\begin{array}{l}0.07 \\
(0.04)\end{array}$ & $\begin{array}{l}0.33 \\
(0.25)\end{array}$ & $\begin{array}{l}3.00 \\
(1.92)\end{array}$ & $\begin{array}{l}1.42 \\
(0.99)\end{array}$ & $\begin{array}{l}0.24 \\
(0.22)\end{array}$ & $\begin{array}{l}0.30 \\
(0.04)\end{array}$ & $\begin{array}{l}0.82 \\
(0.12)\end{array}$ & $\begin{array}{l}0.25 \\
(0.21)\end{array}$ & $\begin{array}{l}0.13 \\
(0.21)\end{array}$ \\
\hline \multicolumn{12}{|c|}{ Monetary Shocks Only } \\
\hline $\begin{array}{c}-0.04 \\
(0.09)\end{array}$ & $\begin{array}{l}0.33 \\
(0.08)\end{array}$ & n.a. & n.a. & n.a. & n.a. & n.a. & n.a. & n.a. & n.a. & n.a. & n.a. \\
\hline \multicolumn{12}{|c|}{ Neutral Technology Shocks Only } \\
\hline n.a. & n.a. & $\begin{array}{c}-0.20 \\
\text { (n.a.) }\end{array}$ & $\begin{array}{l}0.27 \\
(\text { n.a. })\end{array}$ & $\begin{array}{l}1.00 \\
(\text { n.a. })\end{array}$ & $\begin{array}{l}0.88 \\
(\text { n.a. })\end{array}$ & $\begin{array}{c}-1.00 \\
(\text { n.a) }\end{array}$ & n.a. & n.a. & n.a. & n.a. & n.a. \\
\hline \multicolumn{12}{|c|}{ Embodied Technology Shocks Only } \\
\hline n.a. & n.a. & n.a. & n.a. & n.a. & n.a. & n.a. & $\begin{array}{l}0.30 \\
(0.19)\end{array}$ & $\begin{array}{l}0.30 \\
(0.05)\end{array}$ & $\begin{array}{l}0.93 \\
(0.06)\end{array}$ & $\begin{array}{l}0.39 \\
(0.24)\end{array}$ & $\begin{array}{c}-0.24 \\
(0.23)\end{array}$ \\
\hline \multicolumn{12}{|c|}{ Low Cost of Varying Capital Utilization } \\
\hline $\begin{array}{l}.22 \\
(.13)\end{array}$ & $\begin{array}{l}.25 \\
(.06)\end{array}$ & $\begin{array}{l}.87 \\
(.05)\end{array}$ & $\begin{array}{l}.06 \\
(.02)\end{array}$ & $\begin{array}{l}.35 \\
(.19)\end{array}$ & $\begin{array}{l}3.60 \\
(1.72)\end{array}$ & $\begin{array}{l}1.55 \\
(.94)\end{array}$ & $\begin{array}{l}-.10 \\
(.23)\end{array}$ & $\begin{array}{l}.30 \\
(.06)\end{array}$ & $\begin{array}{l}.73 \\
(.19)\end{array}$ & $\begin{array}{l}.36 \\
(.27)\end{array}$ & $\begin{array}{l}.21 \\
(.17)\end{array}$ \\
\hline \multicolumn{12}{|c|}{ High Markup $\lambda_{f}=1.04$} \\
\hline $\begin{array}{c}-0.03 \\
(0.11)\end{array}$ & $\begin{array}{l}0.33 \\
(0.08)\end{array}$ & $\begin{array}{l}0.90 \\
(0.11)\end{array}$ & $\begin{array}{l}0.07 \\
(0.04)\end{array}$ & $\begin{array}{l}0.32 \\
(0.25)\end{array}$ & $\begin{array}{l}2.99 \\
(1.93)\end{array}$ & $\begin{array}{l}1.43 \\
(1.00)\end{array}$ & $\begin{array}{l}0.23 \\
(0.23)\end{array}$ & $\begin{array}{l}0.30 \\
(0.04)\end{array}$ & $\begin{array}{l}0.82 \\
(0.12)\end{array}$ & $\begin{array}{l}0.25 \\
(0.21)\end{array}$ & $\begin{array}{l}0.13 \\
(0.21)\end{array}$ \\
\hline \multicolumn{12}{|c|}{ High Markup $\lambda_{f}=1.20$} \\
\hline $\begin{array}{c}-0.04 \\
(0.11)\end{array}$ & $\begin{array}{l}0.33 \\
(0.09)\end{array}$ & $\begin{array}{l}0.89 \\
(0.12)\end{array}$ & $\begin{array}{l}0.07 \\
(0.04)\end{array}$ & $\begin{array}{l}0.31 \\
(0.26)\end{array}$ & $\begin{array}{l}2.93 \\
(1.98)\end{array}$ & $\begin{array}{l}1.46 \\
(1.03)\end{array}$ & $\begin{array}{l}0.20 \\
(0.24)\end{array}$ & $\begin{array}{l}0.31 \\
(0.04)\end{array}$ & $\begin{array}{l}0.83 \\
(0.11)\end{array}$ & $\begin{array}{l}0.27 \\
(0.20)\end{array}$ & $\begin{array}{l}0.09 \\
(0.20)\end{array}$ \\
\hline \multicolumn{12}{|c|}{ Benchmark (6 lag VAR) } \\
\hline $\begin{array}{l}0.05 \\
(0.12)\end{array}$ & $\begin{array}{l}0.29 \\
(0.07)\end{array}$ & $\begin{array}{l}0.87 \\
(0.06)\end{array}$ & $\begin{array}{l}0.06 \\
(0.02)\end{array}$ & $\begin{array}{l}0.23 \\
(0.27)\end{array}$ & $\begin{array}{l}1.61 \\
(0.85)\end{array}$ & $\begin{array}{l}1.32 \\
(0.76)\end{array}$ & $\begin{array}{l}0.80 \\
(0.14)\end{array}$ & $\begin{array}{l}0.10 \\
(0.05)\end{array}$ & $\begin{array}{l}0.80 \\
(0.11)\end{array}$ & $\begin{array}{l}0.76 \\
(0.62)\end{array}$ & $\begin{array}{c}-0.23 \\
(0.52)\end{array}$ \\
\hline
\end{tabular}




\begin{tabular}{|c|c|c|}
\hline TABLE 4: IMPLIED AVERA & \multicolumn{2}{|r|}{$\frac{1}{1-\xi_{P}}$} \\
\hline Model & Firm-Specific Capital Model & Homogeneous Capital Model \\
\hline Benchmark & 1.51 & 5.60 \\
\hline Benchmark (6 lag VAR) & 1.12 & 3.13 \\
\hline Monetary Shocks Only & 3.59 & 3.64 \\
\hline Neutral Technology Shocks Only & 1.00 & 1.00 \\
\hline Embodied Technology Shocks Only & 1.46 & 6.10 \\
\hline $\begin{array}{l}\text { Low Cost of Varying } \\
\text { Capital Utilization }\end{array}$ & 2.33 & 2.34 \\
\hline Intermediate Markup $\lambda_{f}=1.04$ & 2.24 & 5.52 \\
\hline High Markup $\lambda_{f}=1.20$ & 3.48 & 5.04 \\
\hline
\end{tabular}


Figure 4a: Quasi First Difference of Change in Inflation Versus Log, Marginal Cost

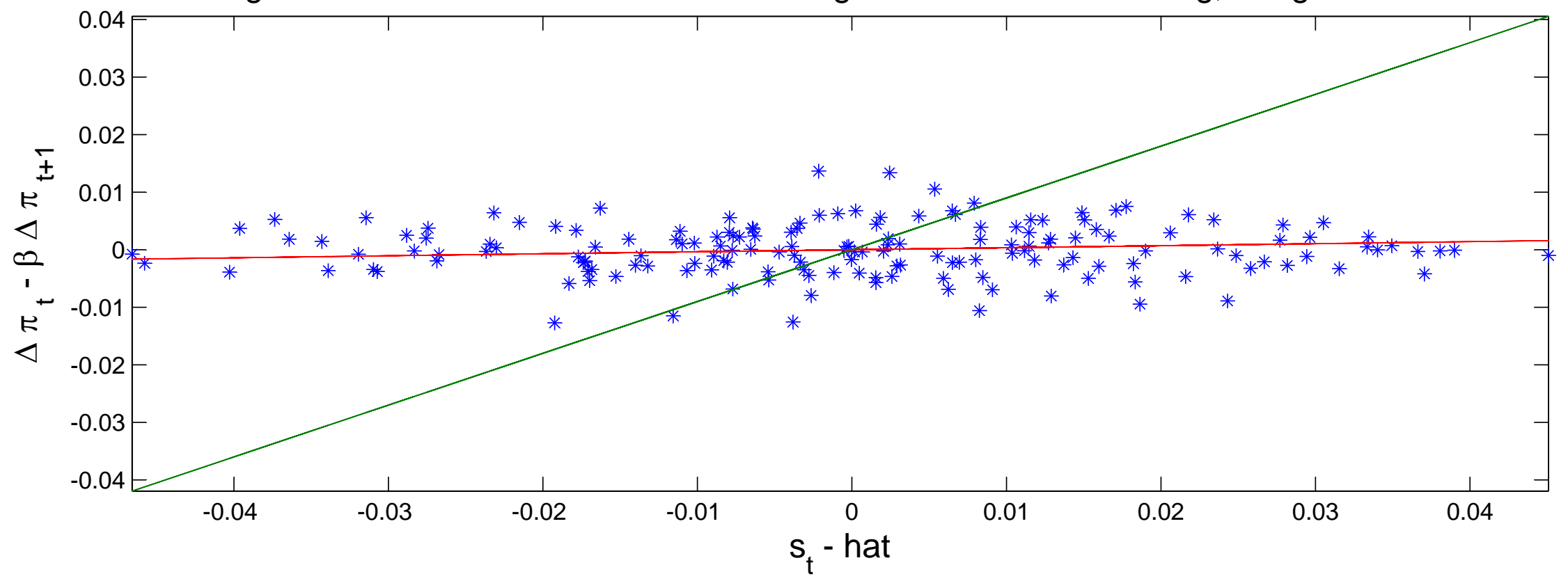

Figure 4b: Projection of Quasi First Difference of the Change in Inflation Versus Projection of Log, Marginal Cost

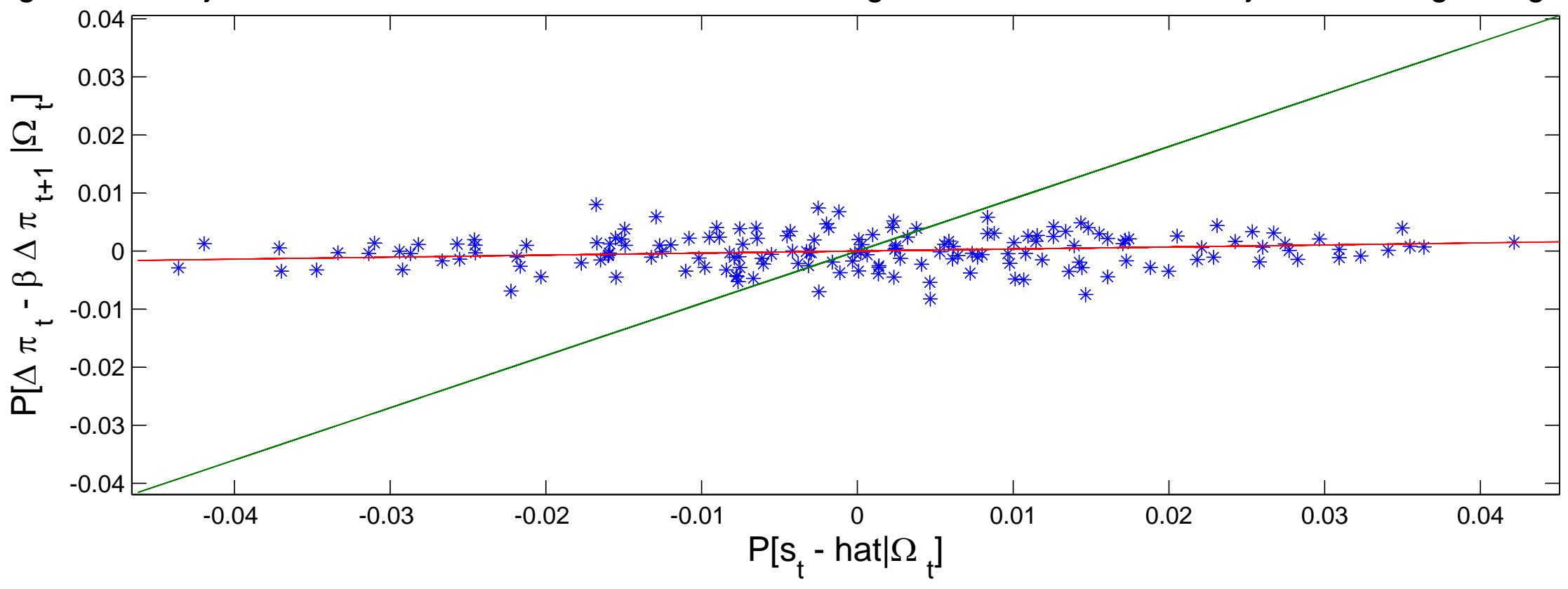


Figure 5: Firm-Specific Capital and the Response of Price to Marginal Cost Shocks

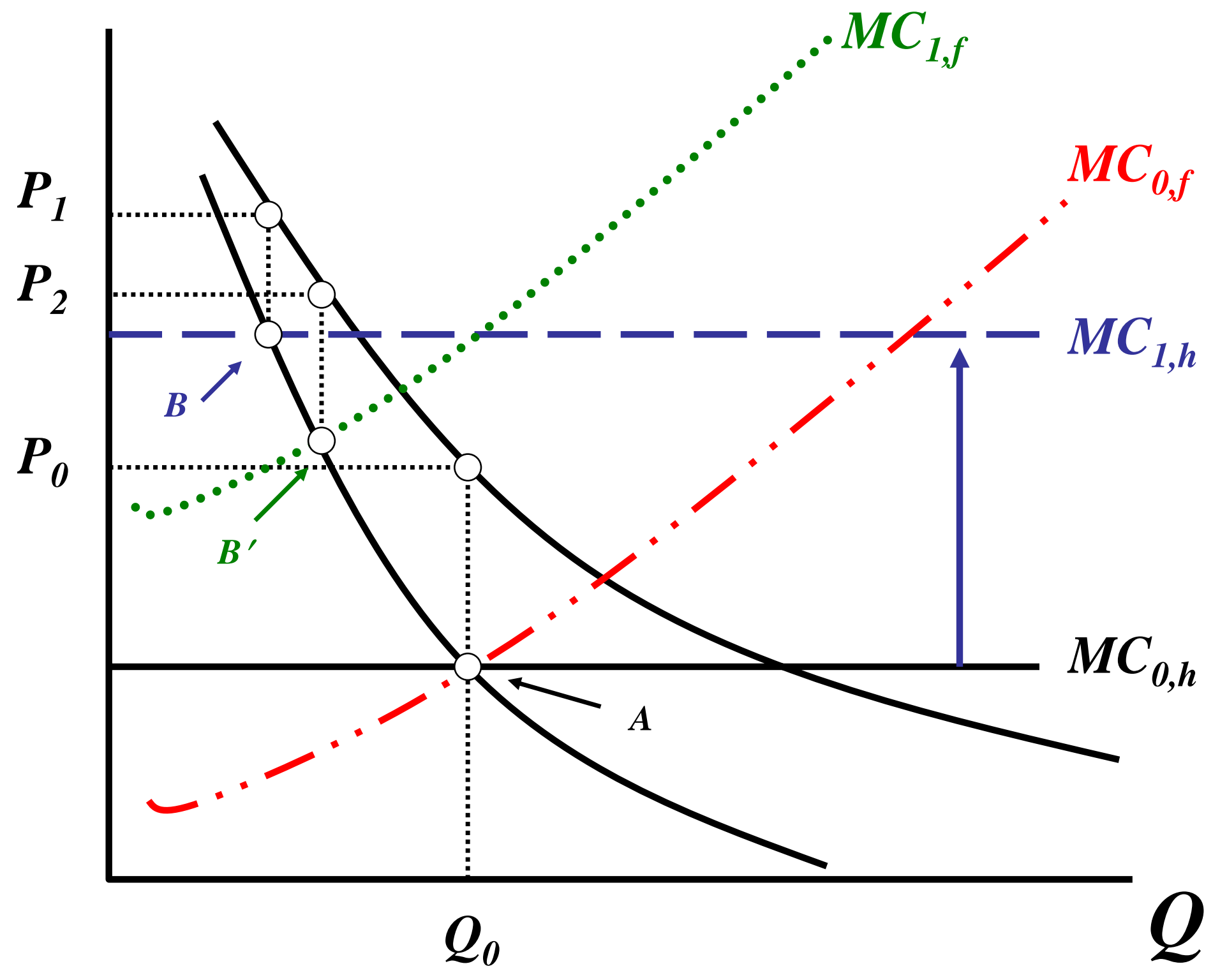


Figure 6: Features of the Distribution of Output and Prices Across Firms

Figure 6a: Share of output and firms in Period 4 Homogeneous Capital Model

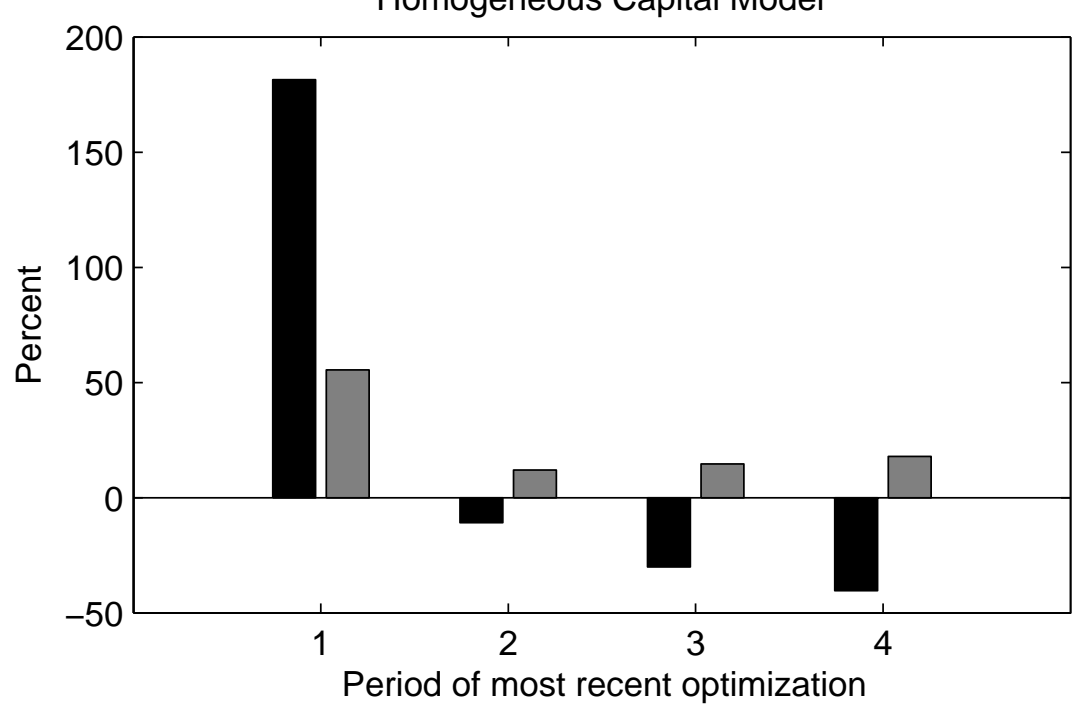

Figure 6c: Share of output and firms in Period 4

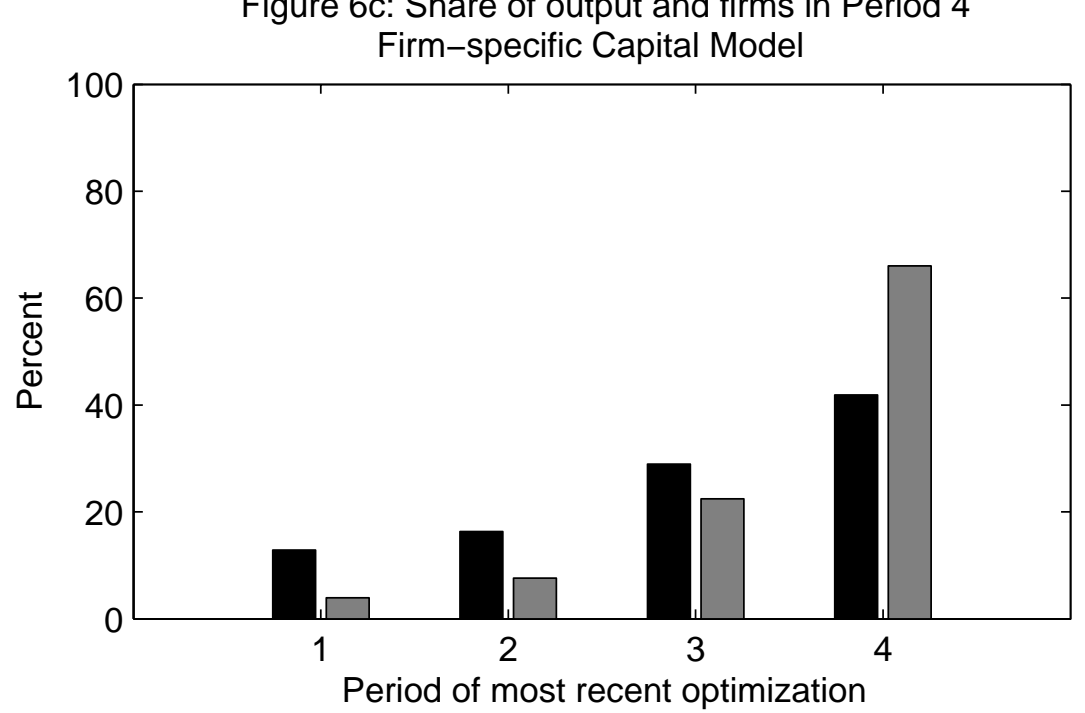

Figure 6b: Average relative price in Period 4 Homogeneous Capital Model

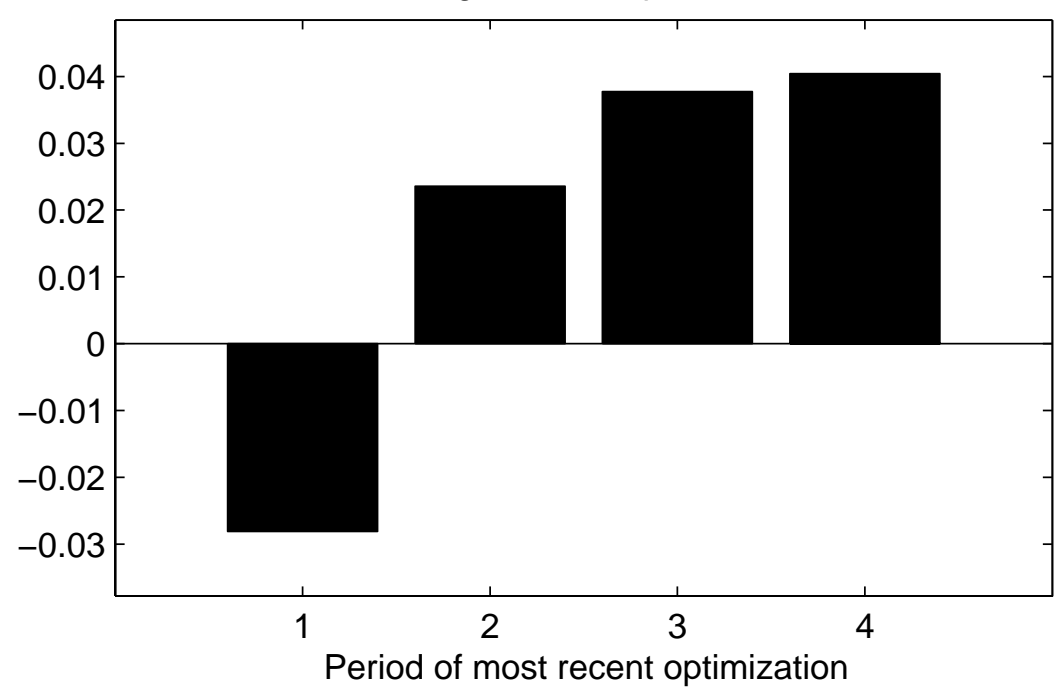

Figure 6d: Average relative price in Period 4 Firm-specific Capital Model

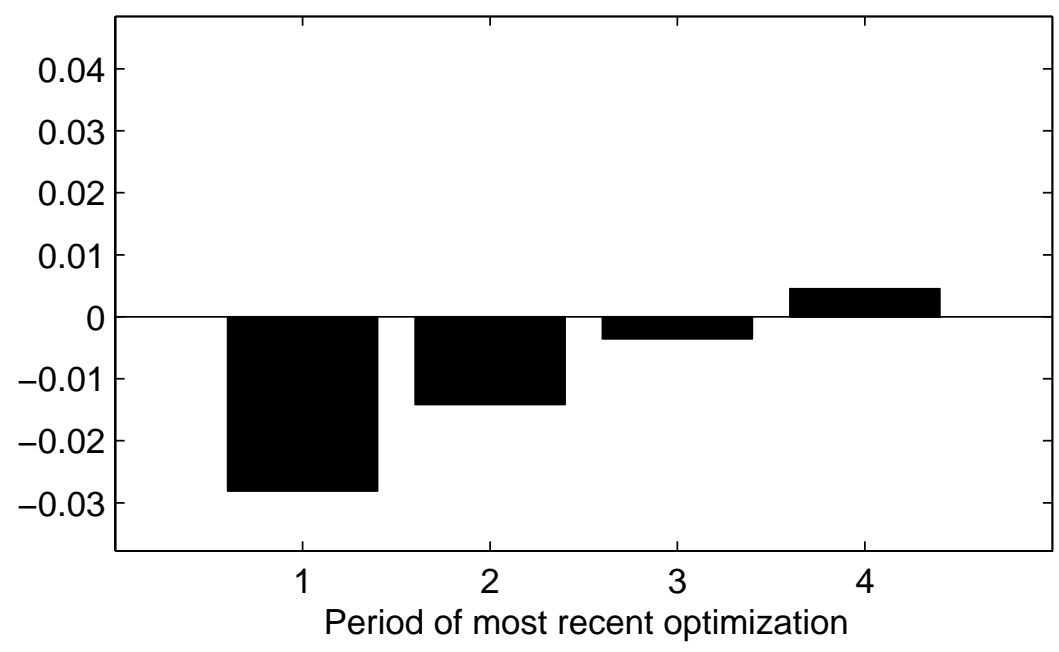


Figure 7: Accuracy of Estimated Impulse Response Functions
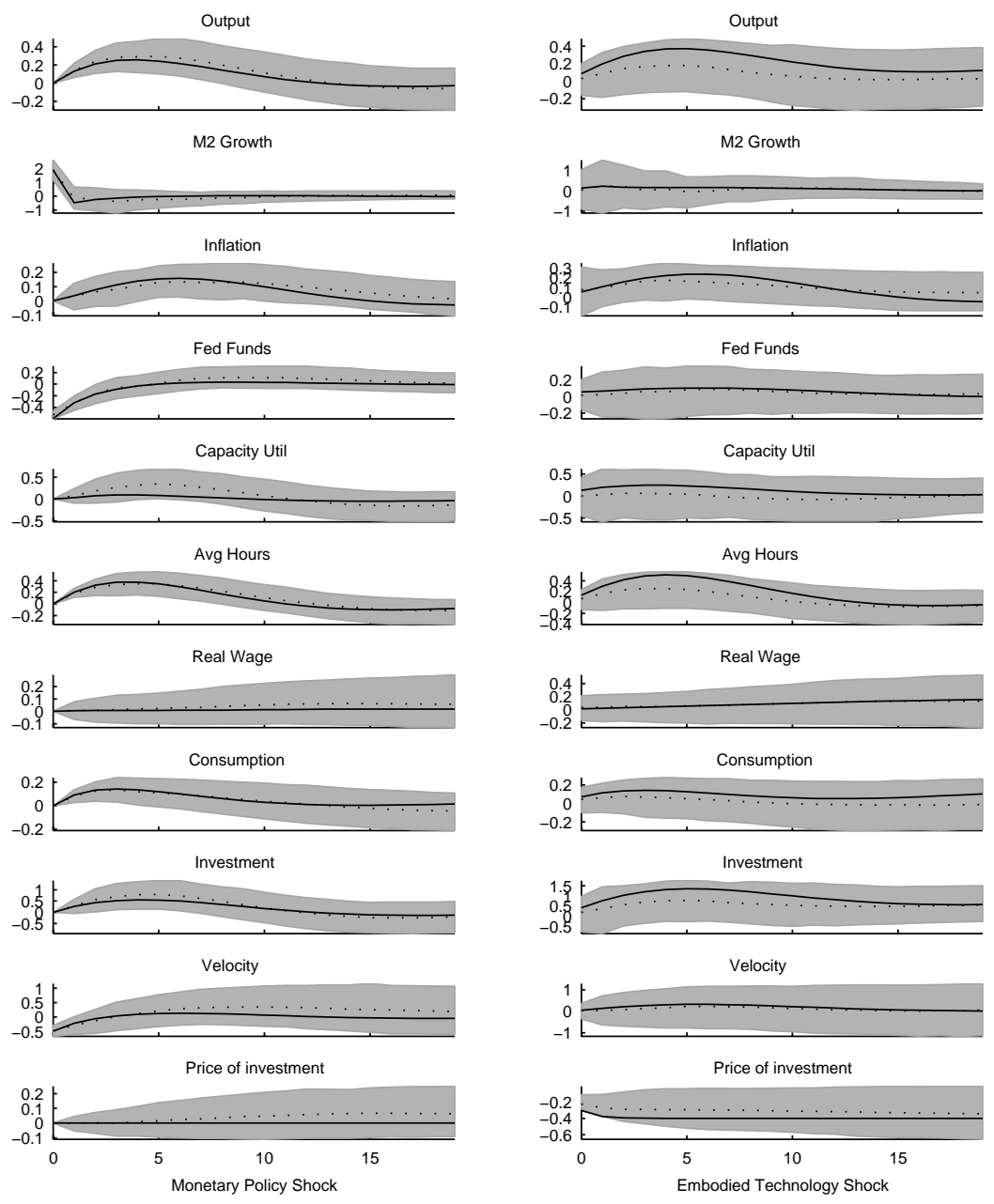

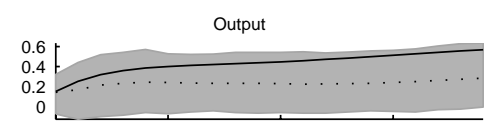

M2 Growth
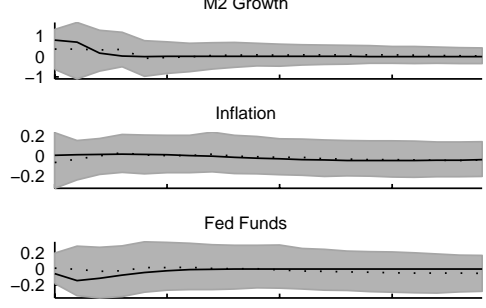

Capacity Util

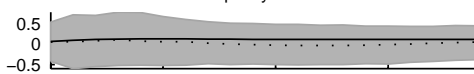

Avg Hours

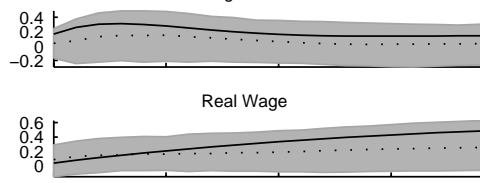

Consumption

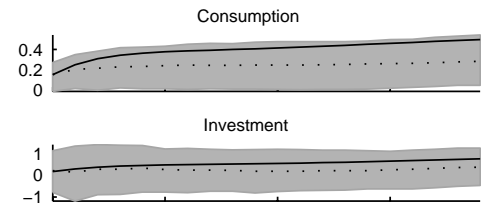

Velocity

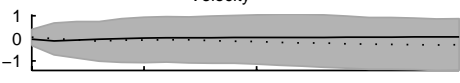

Price of investment

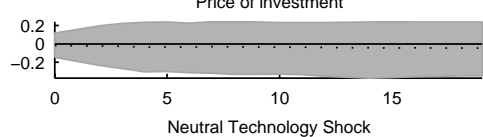

